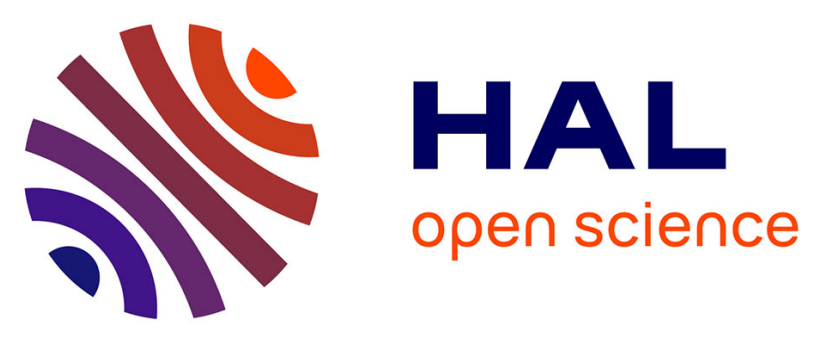

\title{
Surfactant-Free Emulsion Polymerization Stabilized by Ultrasmall Superparamagnetic Iron Oxide Particles Using Acrylic Acid or Methacrylic Acid as Auxiliary Comonomers
}

\author{
Keran Li, Pierre-Yves Dugas, Muriel Lansalot, Elodie Bourgeat-Lami
}

\section{To cite this version:}

Keran Li, Pierre-Yves Dugas, Muriel Lansalot, Elodie Bourgeat-Lami. Surfactant-Free Emulsion Polymerization Stabilized by Ultrasmall Superparamagnetic Iron Oxide Particles Using Acrylic Acid or Methacrylic Acid as Auxiliary Comonomers. Macromolecules, 2016, 49 (20), pp.7609 - 7624. 10.1021/acs.macromol.6b01546 . hal-01716110

\author{
HAL Id: hal-01716110 \\ https://hal.science/hal-01716110
}

Submitted on 7 Oct 2021

HAL is a multi-disciplinary open access archive for the deposit and dissemination of scientific research documents, whether they are published or not. The documents may come from teaching and research institutions in France or abroad, or from public or private research centers.
L'archive ouverte pluridisciplinaire HAL, est destinée au dépôt et à la diffusion de documents scientifiques de niveau recherche, publiés ou non, émanant des établissements d'enseignement et de recherche français ou étrangers, des laboratoires publics ou privés. 


\title{
Surfactant-free emulsion polymerization stabilized by ultrasmall
}

\section{superparamagnetic iron oxide particles using acrylic acid or methacrylic}

\author{
acid as auxiliary comonomers
}

\author{
K. Li, P-Y. Dugas, M. Lansalot, * E. Bourgeat-Lami*
}

Univ Lyon, Université Claude Bernard Lyon 1, CPE Lyon, CNRS, UMR 5265, Chemistry, Catalysis, Polymers and Processes (C2P2), 43 Bvd. du 11 Novembre 1918, F-69616 Villeurbanne, France.

\begin{abstract}
Iron oxide (IO)-based composite latex particles with a patchy IO overlayer were successfully prepared by Pickering emulsion polymerization of acrylic monomers and/or styrene using acrylic acid or methacrylic acid as auxiliary comonomers. The ultrasmall IO particles adsorbed at the latex surface and played the role of a solid stabilizer. The influence of the synthesis conditions on the composite particle size, polymerization kinetics, IO incorporation efficiency and particle morphology was studied. Thermogravimetric analysis indicated that the efficiency of iron oxide incorporation was improved with increasing the suspension $\mathrm{pH}$, the amount of auxiliary comonomer or the IO content, and reached ca. $90 \%$ under optimized conditions. Reducing the initial iron oxide concentration at constant monomer concentration led to an increased particle size and a reduced colloid stability, indicating that the magnetic nanoparticles stabilized the colloidal nanocomposites. Transmission electron microscopy studies confirmed the presence of iron oxide at the particle surface. In the light of these results, a tentative mechanism for Pickering emulsion polymerization using IO nanoparticles as solid stabilizer in the presence of (meth)acrylic acid auxiliary comonomers was proposed.
\end{abstract}

Keywords: Iron oxide, Pickering emulsion polymerization, auxiliary comonomer, patchy, morphology, cryo-TEM. 


\section{INTRODUCTION}

In recent years, there has been an increasing interest in the synthesis of colloidal organic/inorganic hybrids incorporating a variety of inorganic materials. ${ }^{1}$ Among them, magnetic particles have attracted particular attention owing to the great advantages that these materials can offer. $^{2}$ Composite latexes incorporating magnetic nanoparticles [mostly maghemite $\left(\gamma-\mathrm{Fe}_{2} \mathrm{O}_{3}\right)$ and magnetite $\left.\left(\mathrm{Fe}_{3} \mathrm{O}_{4}\right)\right]$, unlike other submicronic latexes, can be handled by an external magnetic field, explaining why these particles have been extensively studied for a range of biomedical applications including magnetic resonance imaging and drug delivery. ${ }^{3}$ Among the techniques the most commonly applied for the synthesis of magnetic composite latexes, emulsion polymerization, a widely used free radical heterogeneous polymerization process, can be considered as one of the most efficient method. ${ }^{4}$ Very recently, a special attention has been dedicated to surfactant-free polymerizations solely stabilized by nanoparticles, due to their simplified composition and preparation steps. ${ }^{5}$ Two processes can be distinguished. The first one is Pickering miniemulsion polymerization. In this process, inorganic particles are used to stabilize miniemulsion droplets following the discovery of $\operatorname{Ramsden}^{6}$ and Pickering ${ }^{7}$ that finelydivided insoluble solid particles can efficiently stabilize emulsions. The sub-micron monomer droplets are prepared in such a way that they efficiently trap the radicals generated in the aqueous phase. Hence, the polymerization takes place in the Pickering stabilized miniemulsion droplets which are subsequently converted into armored nanocomposite latexes of submicrometer size through droplet nucleation. However, the main drawback of this method is that it requires pre-emulsification of the monomer using high-shear devices to create the miniemulsion, which may lead to coagulation of the Pickering stabilizer and highly complicate scaling-up of the process in view of industrial applications. The second process, which we refer to as Pickering emulsion polymerization in this work, is a classical emulsion 
polymerization process in which the conventional emulsifier is replaced by nanosized inorganic solids. The monomer is emulsified as coarse droplets and particles are formed by heterocoagulation between a growing polymer particle and the inorganic solid that adsorb at the surface of the polymer latex particles during the course of the polymerization. ${ }^{8}$ Compared to Pickering miniemulsion polymerization,,${ }^{9,10,11}$ very few papers have been published on the use of iron oxide particles as Pickering stabilizer in conventional emulsion polymerization. $\mathrm{Xu}$ et al. ${ }^{12}$ prepared raspberry-like magnetic polystyrene (PSt) microspheres $(200-600 \mathrm{~nm})$ using 2,2'-azoisobutyramidine dihydrochloride (AIBA) as cationic initiator. The initiator was adsorbed on the surface of poly(methacrylic acid)-functionalized $\mathrm{Fe}_{3} \mathrm{O}_{4}$ nanoparticles at $\mathrm{pH}$ around 9.0, and used to initiate the emulsion polymerization of styrene. Upon growing, the polymer chains became insoluble in the aqueous solution and aggregated on the magnetic nuclei leading to the formation of magnetic PSt microspheres with raspberry-like morphology. The cationic initiator was key in obtaining the targeted morphology as the use of potassium persulfate (an anionic initiator) resulted in polydisperse particles with no IO/polymer interaction. Kim et al. ${ }^{13}$ fabricated core-shell magnetic PSt/inorganic particles by Pickering emulsion polymerization using nanosized $\gamma-\mathrm{Fe}_{2} \mathrm{O}_{3}$ particles as solid stabilizer. Styrene monomer was first added to the $\gamma-\mathrm{Fe}_{2} \mathrm{O}_{3}$ dispersion and agitated vigorously in a homogenizer until the styrene layer was well dispersed in the aqueous phase as emulsified droplets. An aqueous AIBA solution was then added to initiate the polymerization. Images obtained from scanning and transmission electron microscopy (SEM and TEM, respectively) showed PSt $/ \gamma-\mathrm{Fe}_{2} \mathrm{O}_{3}$ composite particles with an uneven surface. According to the authors, styrene droplets were stabilized by $\gamma-\mathrm{Fe}_{2} \mathrm{O}_{3}$ nanoparticles positioned at the water/droplets interface, and droplet polymerization occurred immediately after addition of AIBA. Although TEM and SEM analyses seemed to indicate the presence of IO at the particle surface, the exact mechanism of particle formation is questionable. Indeed, the authors did not give any 
indication on droplet size and stability. Besides, the final particles were quite small (150-300 $\mathrm{nm}$ in diameter) which is not in agreement with a droplet nucleation mechanism as emulsion droplets obtained by simple agitation (even if vigorous) are usually relatively large (even in Pickering emulsions). Finally, there was no information about the IO particles surface chemistry, surface charge or suspension $\mathrm{pH}$, making it difficult to understand what was the driving force for IO adsorption at the monomer/water interface.

In this article, we report the surfactant-free synthesis of polymer/IO composite particles using $\gamma-\mathrm{Fe}_{2} \mathrm{O}_{3}$ as solid stabilizer. Relying on the well-known affinity of carboxylic acids towards iron oxide, methacrylic acid (MAA) and acrylic acid (AA) were selected as auxiliary comonomers. Indeed, previous reports in the literature have indicated that the use of an auxiliary comonomer can promote inorganic particles adhesion to the latex surface. ${ }^{14,15,16,17,18}$ However, to date, their utilization has never been reported for iron oxide. As compared with the previous literature, special attention was paid to the mechanism of the Pickering emulsion polymerization process by studying the effect of the physicochemical parameters (suspension $\mathrm{pH}$, IO content, type of monomer) on the evolution of particle morphology, IO incorporation efficiency and polymerization kinetics. The magnetic properties of the resulting hybrid latexes were also briefly examined.

\section{EXPERIMENTAL SECTION}

\subsection{Materials}

Iron (II) chloride tetrahydrate $\left(\mathrm{FeCl}_{2} \cdot 4 \mathrm{H}_{2} \mathrm{O}, 99 \%\right.$, Aldrich), iron (III) chloride hexahydrate $\left(\mathrm{FeCl}_{3} \cdot 6 \mathrm{H}_{2} \mathrm{O}, 97 \%\right.$, Aldrich), iron (III) nitrate nonahydrate $\left(\mathrm{Fe}\left(\mathrm{NO}_{3}\right)_{3} .9 \mathrm{H}_{2} \mathrm{O}, 98 \%\right.$, Acros Organics), diethyl ether (99.5\%, Aldrich), hydrochloric acid (HCl, $37 \%$, VWR International), nitric acid $\left(\mathrm{HNO}_{3}, 65-70 \%\right.$, VWR International), potassium hydroxide (KOH, Acros 
Organics) and ammonia (20\%, VWR International) were all used as received. The monomers, methyl methacrylate (MMA, 99\% Aldrich), styrene (St, 99\%, Acros), n-butyl acrylate (BA, 99\%, Aldrich) and the auxiliary comonomers, methacrylic acid (MAA, 99.5\%, Acros Organics) and acrylic acid (AA, 99\%, Aldrich) were used without further purification. 2,2'-Azobis[2-(2-imidazolin-2-yl) propane] dihydrochloride (ADIBA, Wako Pure Chemical Industries, Ltd) was used as radical initiator. Deionized water (Purelab Classic UV, ElgaLabWater) was used for all experiments.

\subsection{Methods}

Synthesis of ultrasmall superparamagnetic iron oxide particles. IO nanoparticles were prepared using the Massart approach which involves the aqueous coprecipitation of iron chlorides under alkaline conditions. ${ }^{19,20}$ In a beaker, $13 \mathrm{~g}(0.0481 \mathrm{~mol})$ of $\mathrm{FeCl}_{3}$ and $7.2 \mathrm{~g}$ $(0.0362 \mathrm{~mol})$ of $\mathrm{FeCl}_{2}$ were dissolved in $40 \mathrm{~mL}$ of deionized water and $4 \mathrm{~mL}$ of hydrochloric acid (37 wt\% water solution) to give a $\mathrm{Fe}(\mathrm{II}): \mathrm{Fe}(\mathrm{III})$ stoichiometric ratio of 3:4. This solution was stirred until complete dissolution, and poured in a four-necked round-bottom flask equipped with a mechanical stirrer $(500 \mathrm{rpm})$ followed by quick injection of $40 \mathrm{~mL}$ of $20 \mathrm{wt} \%$ aqueous $\mathrm{NH}_{4} \mathrm{OH}$ solution and stirring for 30 minutes to facilitate the hydrolysis and condensation of iron precursors. A black precipitate was formed immediately indicating the formation of IO nanoparticles. The resulting black precipitate was collected with a permanent magnet (Supermagnete Q-51-51-25-N, Germany), and after decantation of the supernatant, the residue was washed with deionized water $(40 \mathrm{~mL})$ and $\mathrm{HNO}_{3}(70 \mathrm{wt} \%$ solution, $5.2 \mathrm{~mL})$. The oxidation to maghemite was then completed by adding a solution of $\mathrm{Fe}\left(\mathrm{NO}_{3}\right)_{3}(12.92 \mathrm{~g}$, $0.0534 \mathrm{~mol})$ dissolved in deionized water $(32 \mathrm{~mL})$ and heating to $80^{\circ} \mathrm{C}$ under stirring at 500 rpm for $30 \mathrm{~min}$. The resulting orange precipitate was again collected with the aid of a magnet, and peptized by adding $10.4 \mathrm{~mL}$ of $\mathrm{HNO}_{3}(70 \mathrm{wt} \%)$ and $80 \mathrm{~mL}$ of deionized water. The color 
of the suspension turned from orange to orange-brown. The mixture was stirred manually with a teflon spatula and the nanoparticles were again isolated from the solution with the help of a magnet. Finally, the residue was washed several times first with acetone, then with diethyl ether, and finally dispersed in $40 \mathrm{~mL}$ of deionized water. Any remaining diethyl ether was removed by evaporation under the fume hood. The $\mathrm{pH}$ of the final suspension was 2.2.

Preparation of magnetic microspheres via Pickering emulsion polymerization. Emulsion polymerizations were performed in a glass-jacketed reactor equipped with a condenser and a nitrogen inlet. As a representative example (run 6 in Table 1), the IO suspension (16.13 g, which is equivalent to $2.0 \mathrm{~g}$ dry $\mathrm{IO})$ was diluted with water $(75.87 \mathrm{~g})$. The mixture was placed in the reactor, followed by the addition of MAA $(0.13 \mathrm{~g})$ dissolved in water $(5 \mathrm{~g})$. This suspension was deoxygenated by purging with nitrogen for $30 \mathrm{~min}$. In the meantime, MMA (20 g) was deoxygenated for $30 \mathrm{~min}$ and added to the IO suspension under vigorous stirring while the temperature was raised to $70{ }^{\circ} \mathrm{C}$. The ADIBA initiator $(0.2 \mathrm{~g}, 1.0 \mathrm{wt} \%$ based on monomer) was dissolved in $5 \mathrm{~g}$ of degassed water and added to the reactor. This was considered to be the zero time of the polymerization. The polymerization was conducted for 2 hours under mechanical stirring at $350 \mathrm{rpm}$. Samples were taken during polymerization to follow the evolution of the conversion as a function of time, and of the particle size and particle number as a function of the conversion.

MAA adsorption isotherms. MAA adsorption onto IO was investigated at $25{ }^{\circ} \mathrm{C}$ for two different $\mathrm{pH}$ values $(\mathrm{pH}=2.2$ and 4.5) using the depletion method. Briefly, equivolumes of the magnetic suspension and MAA solutions were mixed to cover MAA concentrations ranging from 1 to $10 \mathrm{~g} \mathrm{~L}^{-1}$ (equivalent to $3.5-35 \mu \mathrm{mol} \mathrm{m} \mathrm{m}^{-2}$ relative to IO surface given a specific surface area, $\mathrm{S}_{\text {spec }}$, of $166 \mathrm{~m}^{2} \mathrm{~g}^{-1}$ as determined by BET and $M_{\mathrm{n} \text { MAA }}=86.06 \mathrm{~g} \mathrm{~mol}^{-1}$ ) 
while maintaining a fixed IO content of $20 \mathrm{~g} \mathrm{~L}^{-1} \cdot \mathrm{pH}$ adjustment to 4.5 was carried out by dialyzing the IO suspension against deionized water in 6 8000 Daltons dialysis tubes. Indeed, direct addition of $\mathrm{NaOH}$ to the $\mathrm{IO}$ suspension led to particles aggregation. The mixtures were left stirring for $30 \mathrm{~min}$ to reach the adsorption equilibrium, and ultracentrifuged at $80000 \mathrm{rpm}$ (Allegra $^{\mathrm{TM}}$ 64R centrifuge) for $120 \mathrm{~min}$. The MAA concentration in each supernatant was determined by UV analysis using a pre-established calibration curve $\left(\lambda_{\max }=400 \mathrm{~nm}\right)$ and the adsorbed amount was then calculated by difference between the initial and equilibrium concentrations according to:

$$
\text { Adsorbed MAA }\left(\mathrm{mg} \mathrm{g}^{-1}\right)=\frac{\left(C_{0}-C_{e}\right) V}{m} \times 1000
$$

where $\mathrm{C}_{0}\left(\mathrm{~g} \mathrm{~L}^{-1}\right)$ is the initial MAA concentration, $\mathrm{C}_{\mathrm{e}}\left(\mathrm{g} \mathrm{L}^{-1}\right)$ designates the MAA equilibrium concentration in the supernatant, $\mathrm{V}(\mathrm{L})$ is the volume of solution and $\mathrm{m}(\mathrm{g})$ is the mass of iron oxide.

IO incorporation efficiency and latex surface coverage by IO. Iron oxide incorporation efficiencies were determined by comparing the IO content of the IO-armored particles after removal of the free IO by centrifugation at $7500 \mathrm{rpm}$ for $15 \mathrm{~min}$, with the original IO content $\left(\mathrm{m}_{\mathrm{IO}}\right)$ used in the corresponding polymerization experiments. The rotational speed $(7500 \mathrm{rpm})$ was carefully selected to enable selective sedimentation of the latex particles while retaining the free IO in the supernatant. The estimated error in the final iron oxide incorporation efficiencies was $+/-2 \%$. The IO content of the purified particles was determined by TGA on a TA instruments Q5000 IR. Typically, $10 \mathrm{mg}$ of the dried sample were accurately weighed and heated from 25 to $800{ }^{\circ} \mathrm{C}$ at a rate of $10{ }^{\circ} \mathrm{C} \min ^{-1}$ under an oxygen atmosphere. The IO incorporation efficiency $(I E, \%)$ was then calculated as follows:

$$
I E(\%)=\frac{I O_{\mathrm{TGA}} \times\left(100-I O_{\text {theo }}\right)}{I O_{\text {theo }} \times\left(100-I O_{\mathrm{TGA}}\right)} \times 100
$$


where $I O_{\mathrm{TGA}}(\%)$ is the $\mathrm{IO}$ content of the purified composite particles and $I O_{\text {theo }}(\%)$ is the theoretical IO content before centrifugation determined from the amount of IO initially introduced and the monomer conversion determined by gravimetric analysis (after subtracting the mass of IO and initiator).

$$
I O_{\text {theo }}(\%)=\frac{m_{\mathrm{IO}}}{\left(m_{\mathrm{IO}}+m_{\text {monomer }} \times \frac{\text { Conversion }}{100}\right)} \times 100
$$

with $m_{\mathrm{IO}}$ corresponding to the total mass of IO introduced and $m_{\text {monomer }}$ to the total mass of monomer.

Combining equations (2) and (3), it turns:

$$
I E(\%)=\frac{m_{\text {monomer }} \times \text { Conversion } \times I O_{T G A}}{m_{\mathrm{IO}}\left(100-I O_{T G A}\right)}
$$

The surface coverage of the latex particles by IO (Cov. \%) was calculated using the IE value, assuming that the surface area occupied by one IO nanoparticle at the polymer particle surface was equal to the cross-sectional area of a plane bisecting that nanoparticle. The surface coverage can then be expressed as:

$$
\operatorname{Cov} .(\%)=\frac{1}{4}\left(\frac{m_{\mathrm{IO}} \times I E}{m_{\text {monomer }} \times \text { Conversion }}\right)\left(\frac{\rho_{\text {polymer }}}{\rho_{\mathrm{IO}}}\right)\left(\frac{D_{\mathrm{h}}}{D_{\mathrm{IO}}}\right) \times 100
$$

where $\rho_{\mathrm{IO}}$ is the apparent density of the IO nanoparticles $\left(\rho_{\mathrm{IO}}=5.24 \mathrm{~g} \mathrm{~cm}^{-3}\right)^{21}$ and $D_{\mathrm{IO}}$ their diameter determined by TEM, $\rho_{\text {polymer }}$ is the polymer density and $D_{\mathrm{h}}$ the composite particles diameter determined by DLS.

\subsection{Characterization techniques}

Fourier Transform InfraRed (FTIR) spectroscopy. FTIR spectra were recorded from $\mathrm{KBr}$ pellets at room temperature using a Nicolet iS50 FTIR spectrometer from Thermo Scientific 
equipped with a deuterated triglycine sulfate (DTGS) detector. Background and sample were acquired using $32 \mathrm{scans}$ at a spectral resolution of $4 \mathrm{~cm}^{-1}$ from 4000 to $400 \mathrm{~cm}^{-1}$. Spectral data were obtained using OMNIC Software from Thermo Scientific.

X-Ray Diffraction (XRD) analyses. XRD measurements were performed on PANalytical X'Pert Pro diffractometer equipped with a X'Celerator Scientific detector and a $\mathrm{Cu}$ anticathode $\left(K \alpha_{1} / K \alpha_{2}\right)$. The instrument was used in the theta/theta reflection mode, fitted with a nickel filter, 0.04 radian Soller slits, $10 \mathrm{~mm}$ mask, $1 / 2^{\circ}$ fixed divergence slit, and $1^{\circ}$ fixed antiscatter slit. The diffracted beam was detected (detector active length $=2.122^{\circ}(2 \theta)$ ) over a range of $5-70^{\circ}(2 \theta)$ with a step size of $0.0167^{\circ}$ and a counting time of $350 \mathrm{~s} / \mathrm{step}$. The size of the iron oxide nanocrystallite was estimated from the XRD data using the DebyeScherrer equation:

$$
D(\AA)=\frac{0.9 \lambda}{\beta \cos \theta}
$$

where $\mathrm{D}$ is the crystallite size $(\AA), \lambda$ is the wavelength of $\mathrm{X}$-rays $(\mathrm{Cu} \mathrm{K \alpha}: \lambda=1.5418 \AA), \theta$ is the diffraction angle, and $\beta$ is the full width at half-maximum (in radians).

Dynamic Light Scattering (DLS). The particle size (hydrodynamic diameter, $D_{\mathrm{h}}$ ) was measured by DLS using the Zetasizer NanoZS instrument from Malvern. The data were collected at $173^{\circ}$ scattering angle using the fully automatic mode of the Zetasizer system, and depending on the size distribution, either the monomodal cumulant analysis or the CONTIN analysis was performed. The broadness of the distribution was given by a dimensionless number called poly value determined from the autocorrelation function using the second order method of cumulant analysis (the higher this value, the broader the size distribution). The number of polymer or composite particles per liter of latex suspension at the end of the polymerization, $N_{\mathrm{p}}\left(\mathrm{L}^{-1}\right)$, was calculated using $D_{\mathrm{h}}$ according to the following equation: 


$$
N_{\mathrm{p}}\left(\mathrm{L}^{-1}\right)=\frac{6 C_{\text {polymer }(\text { composite })} 10^{21}}{\rho_{\text {polymer }(\text { composite })} \pi D_{\mathrm{h}}^{3}}
$$

where $C_{\text {polymer (composite) }}\left(\mathrm{g} \mathrm{L}^{-1}\right)$ is the polymer (or composite) concentration and $\rho_{\text {polymer (composite) }}$ $\left(\mathrm{g} \mathrm{cm}^{-3}\right)$ is the density of the polymer or of the composite latex particles, respectively. The composite particle concentration was determined from the IO content in the particles determined by TGA and the polymer concentration determined by gravimetry as follows:

$$
C_{\text {composite }}\left(g^{-1}\right)=\frac{[\text { Monomer }]}{100} \text { Conversion }+\frac{[I O]}{100} I E
$$

where [Monomer] and [IO] $\left(\mathrm{g} \mathrm{L}^{-1}\right)$ designate the initial monomer and IO concentrations, respectively. The density of the composite particles was determined using the equation (9) as:

$$
\rho_{\text {composite }}=\frac{1}{\frac{f_{I O}}{\rho_{I O}}+\frac{f_{\text {polymer }}}{\rho_{\text {polymer }}}}
$$

where $f_{I O}$ and $f_{\text {polymer }}$ are respectively the weight fractions of IO and polymer in the composite particles.

$$
f_{I O}=\frac{[I O] I E}{100 C_{\text {composite }}} \text { and } f_{\text {polymer }}=\frac{[\text { Monomer }] \text { Conversion }}{100 C_{\text {composite }}}
$$

The calculation of $\mathrm{C}_{\text {composite }}$ during the course of the polymerization was however not possible as IE was not determined for each withdrawn samples, and was only determined for the final latexes. All the plots showing the evolution of $N_{\mathrm{p}}$ versus conversion were thus built using $\mathrm{C}_{\text {polymer }}$ in equation (7).

Zeta potential measurements. Zeta potential measurements were performed with the Zetasizer Nano ZS instrument from Malvern. Two kinds of particles were analyzed: i) pristine IO and ii) IO nanoparticles after MAA adsorption. All measurements were performed by adding a few drop of the suspension to an aqueous solution of $10^{-3} \mathrm{~mol} \mathrm{~L}^{-1} \mathrm{KNO}_{3}$. In the case of pristine IO, a stock suspension of the IO nanoparticles in deionized water was first 
homogenized by ultrasonication for $15 \mathrm{~min}$ and the $\mathrm{pH}$ of the measuring solution was adjusted within the range of $\mathrm{pH} 3$ to $\mathrm{pH} 10$ by using $10^{-3} \mathrm{~mol} \mathrm{~L}^{-1}$ aqueous solutions of $\mathrm{HNO}_{3}$ or $\mathrm{KOH}$, respectively.

Transmission Electron Microscopy analyses (TEM and cryo-TEM). TEM analyses were carried out at the Centre Technologique des Microstructures (CT $\mu$ ), platform of the Université Claude Bernard Lyon 1, Villeurbanne, France. A drop of the diluted IO or composite latex suspension was deposited on a carbon/Formvar-coated copper grid and the solvent was allowed to evaporate. The analysis was carried out at room temperature with a Philips CM120 microscope operating at an accelerating voltage of $80 \mathrm{kV}$. The number-average and weightaverage particle diameters $\left(D_{\mathrm{n}}\right.$ and $D_{\mathrm{w}}$, respectively) and the polydispersity index (PDI = $\left.D_{\mathrm{w}} / D_{\mathrm{n}}\right)$ of the pristine IO or of the latex particles were calculated using $D_{\mathrm{n}}=\Sigma \mathrm{n}_{\mathrm{i}} D_{\mathrm{i}} / \Sigma \mathrm{n}_{\mathrm{i}}$ and $D_{\mathrm{w}}$ $=\Sigma \mathrm{n}_{\mathrm{i}} D_{\mathrm{i}}^{4} / \Sigma \mathrm{n}_{\mathrm{i}} D_{\mathrm{i}}{ }^{3}$, where $\mathrm{n}_{\mathrm{i}}$ is the number of particles with diameter $D_{\mathrm{i}}$. A minimum of 150 particles was counted for each batch. To prevent particles deformation (for soft polymer compositions) and/or the deleterious effect of radiation (PMMA is known to be particularly sensitive to electron damage), and allow reliable determination of particle size and morphology, some of the composite latex particles were characterized by cryogenictransmission electron microscopy (cryo-TEM). The diluted samples were dropped onto 300 Mesh holey carbon films (Quantifoil R2/1) and quench-frozen in liquid ethane using a cryoplunge workstation (made at LPS Orsay). The specimens were then mounted on a precooled Gatan 626 specimen holder, transferred in the microscope (Phillips CM120) and observed at an accelerating voltage of $120 \mathrm{kV}$.

Magnetic measurements. A vibrating sample magnetometer (VSM, BHV-55) was used to investigate the magnetic properties of the IO nanoparticles and of the composite latexes by 
measuring the magnetization $(r)$ as a function of the magnetic field intensity $(H)$ from 21 to 0 kOe, at room temperature using the Weiss extraction method. ${ }^{22}$ This dynamic method makes use of the variation of flux induced in a coil when moving the sample in the field. Measurements were performed on dried samples. Specific magnetization $\left(M\right.$ in emu $\left.\mathrm{g}^{-1}\right)$ of a given sample was defined as:

$$
M=\frac{4300 \times \sigma \times \alpha}{m}
$$

where 4300 was the apparatus constant, $m$ the mass of the sample $(\mathrm{g}), \delta$ the raw electric signal value (a.u.), and $\alpha$ the correction of the magnetic image for strong magnetic fields. $M_{\mathrm{S}}$, the specific saturation magnetization was obtained by extrapolation of $M$ for strong magnetic fields $(1 / \mathrm{H} \rightarrow 0)$.

\section{RESULTS AND DISCUSSION}

\subsection{Synthesis of ultrasmall iron oxide magnetic nanoparticles}

A stable dispersion of ultrasmall superparamagnetic iron oxide nanoparticles in water, also called a ferrofluid, was prepared by the coprecipitation of metallic salts according to the method of Massart et al., ${ }^{19}$ which is probably the simplest and most efficient chemical pathway to obtain magnetic nanoparticles. The recipe relies on the synthesis of $\mathrm{Fe}_{3} \mathrm{O}_{4}$ (magnetite) particles by the coprecipitation of ferrous and ferric iron salts in an alkaline environment, followed by oxidation of magnetite into maghemite $\left(\gamma-\mathrm{Fe}_{2} \mathrm{O}_{3}\right)$ using $\mathrm{Fe}\left(\mathrm{NO}_{3}\right)_{3} / \mathrm{HNO}_{3}$. Zeta potential measurements indicated a net positive surface charge $(\zeta=+$ $50 \mathrm{mV}$ at $\mathrm{pH}$ 2.2) responsible for the colloidal stability of the sol, and an isoelectric point (IEP) of about 7.4 (Figure 1a) consistent with the literature value of 7.5 for maghemite. ${ }^{23}$ The protonated surface hydroxyl groups are counterbalanced by non-flocculating nitrate counter- 
ions as shown by FTIR measurements (Figure S1 in the Supporting Information). TEM analysis showed somewhat irregular maghemite crystallites with a number-average diameter $D_{\mathrm{n}}=5.6 \mathrm{~nm}$, and a polydispersity index $\left(D_{\mathrm{w}} / D_{\mathrm{n}}\right)$ of 1.29 as determined by statistical analyses of more than 160 particles (Figure $1 \mathrm{~b}$ ). XRD confirmed the crystalline structure and gave a crystallite size of $6.9 \mathrm{~nm}$ in good agreement with the TEM measurements indicating that the particles were monocrystalline.

a

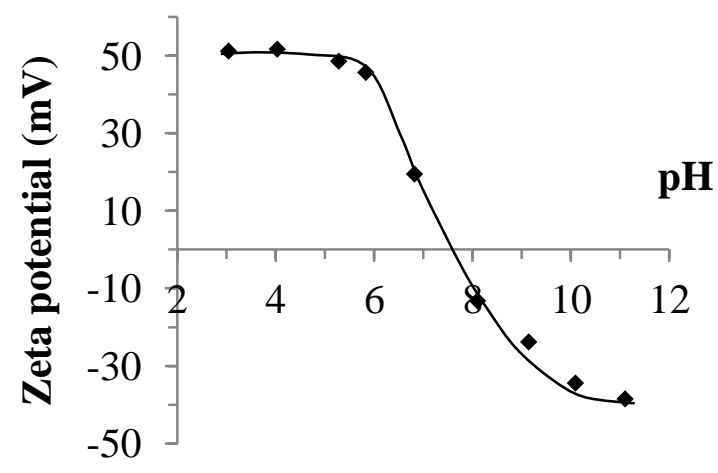

b

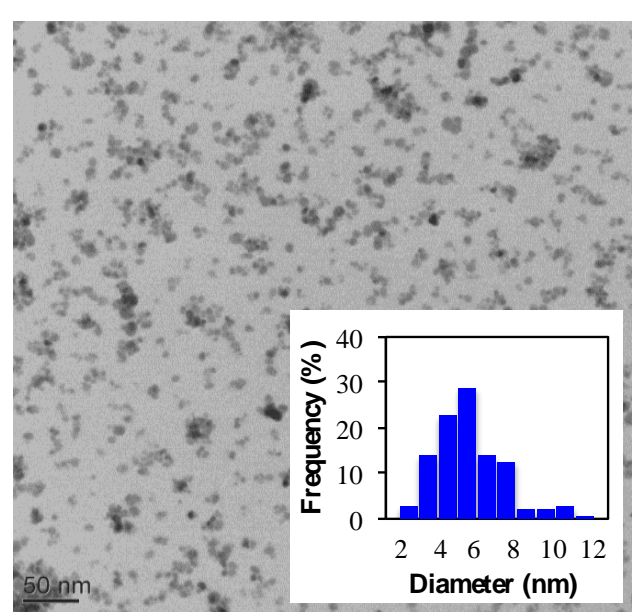

Figure 1. a) $\zeta$ potential of pristine IO nanoparticles as a function of $\mathrm{pH}\left([\mathrm{KCl}]=10^{-3} \mathrm{M}\right)$ and b) TEM image and size histogram of the IO nanoparticles used in this work.

\subsection{Synthesis of magnetic composite microspheres}

The aim of this study was to form magnetic composite microspheres by Pickering emulsion polymerization of various monomers using IO nanoparticles as solid stabilizer. Several authors have shown that the surface chemistry of the inorganic particles plays a significant role in Pickering emulsion polymerization. Indeed, inorganic colloids are too hydrophilic for the oligomers formed in water to adhere irreversibly to their surface, which most often results in binary blends of inorganic and polymer particles. This wettability issue can be overcome by the use of small amounts of hydrophilic comonomers (so-called auxiliary comonomers). 
The role of the auxiliary comonomer is to create favorable interactions between the growing polymer chains and the inorganic surface. ${ }^{15,24}$ Relying on the well-known affinity of carboxylic acids towards iron oxide, ${ }^{25,26}$ MAA and AA have been selected as auxiliary comonomers in the present study. The effect of auxiliary comonomer concentration, IO content, suspension $\mathrm{pH}$ and type of hydrophobic monomer on the polymerization kinetics, the particle size, the IO incorporation efficiency and the composite particle morphology was studied in detail, and the results were compared to the ones obtained under the same conditions in the absence of IO.

\subsubsection{MAA as auxiliary comonomer}

In a first study, control experiments were performed to assess the role of both IO and MAA in the surfactant-free emulsion polymerization of MMA (Table 1).

The polymerization conducted in the absence of both IO and MAA at $\mathrm{pH} 5.9$ (run 1) gave stable PMMA latex particles with diameters of around $420 \mathrm{~nm}$. From the TEM results, the particles are spherical and uniform in size (Figure S2 in the Supporting Information). Such a narrow particle size distribution is characteristic of surfactant-free emulsion polymerization.

Table 1. Recipes and results for the synthesis of pure polymer and composite latex particles by surfactant-free emulsion polymerization of MMA in the presence of MAA. ${ }^{a}$

\begin{tabular}{|c|c|c|c|c|c|c|c|c|c|c|}
\hline Run & $\underset{\left(\mathrm{g} \mathrm{L}^{-1}\right)}{\mathbf{I O}}$ & $\begin{array}{c}\text { MAA } \\
\left(\mathrm{g} \mathrm{L}^{-1}\right)\end{array}$ & 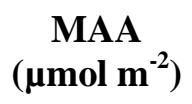 & $\mathrm{pH}_{\mathrm{i}}{ }^{b}$ & $\begin{array}{c}\text { Conv. } \\
(\%)\end{array}$ & $\underset{(\mathbf{n m})^{c}}{D_{\mathbf{h}}}$ & Poly $^{c}$ & $\begin{array}{c}N_{\mathrm{p}} \\
\left(\mathbf{L}^{-1}\right)^{d}\end{array}$ & $\begin{array}{c}I E \\
(\%)^{e}\end{array}$ & $\begin{array}{l}\text { Cov } \\
(\%)^{f}\end{array}$ \\
\hline 1 & 0 & 0 & I & 5.9 & 100 & 420 & 0.01 & $4.410^{15}$ & I & I \\
\hline 2 & 0 & 1.4 & I & 3.1 & 100 & 473 & 0.07 & $3.110^{15}$ & I & I \\
\hline 3 & 0 & 1.4 & I & $2.2^{g}$ & 100 & 624 & 0.04 & $1.310^{15}$ & I & I \\
\hline $4^{h}$ & 0 & 1.4 & I & 2.2 & 100 & 586 & 0.07 & $1.610^{15}$ & I & I \\
\hline 5 & 20 & 0 & 0 & 2.2 & 100 & 451 & 0.07 & $3.510^{15}$ & I & I \\
\hline 6 & 20 & 1.4 & 5 & 2.2 & 99 & 267 & 0.04 & $1.710^{16}$ & 20.4 & 5.5 \\
\hline
\end{tabular}

${ }^{a}$ All experiments were carried out for $2 \mathrm{~h}$ with MMA $=20 \mathrm{wt} \% / \mathrm{water}, \mathrm{ADIBA}=1 \mathrm{wt} \% / \mathrm{MMA}$ and $\mathrm{T}=70{ }^{\circ} \mathrm{C} .{ }^{b}$ $\mathrm{pH}$ value of the aqueous phase or of the IO suspension. ${ }^{c}$ Determined by DLS. ${ }^{d}$ Calculated using equation (7). ${ }^{e}$ Calculated using equation (4). ${ }^{f}$ Calculated using equation (5). ${ }^{g} \mathrm{pH}$ value was adjusted by addition of $\mathrm{HNO}_{3} .{ }^{h}$ Polymerization carried out in the continuous phase of the IO suspension after removing IO by centrifugation. 
Unexpectedly, the polymerization performed in the presence of MAA resulted in bigger particles $\left(D_{\mathrm{h}}=473 \mathrm{~nm}\right.$, run 2$)$ that still displayed a narrow size distribution. This can be explained by the low $\mathrm{pH}$ of the reaction. Indeed, more oligoradicals are initially formed in the presence of MAA due to the increased monomer concentration in water resulting in a larger number of primary particles. However, the MAA units, which are located both inside and at the surface of the particles, are non-ionized at $\mathrm{pH} 2.5$, and cannot provide efficient colloidal stability. The primary particles thus aggregate into larger entities. According to Smoluchowski's theory, ${ }^{27}$ the rate of particle aggregation scales with the square of the particle concentration. Consequently, the higher the number of primary particles, the larger the final particle size. Moreover, decreasing the suspension $\mathrm{pH}$ to 2.2 by adding $\mathrm{HNO}_{3}$ to reach a $\mathrm{pH}$ close to that of the IO suspension resulted in even larger particles around $620 \mathrm{~nm}$ in diameter (run 3). This was likely due to the concomitant increase of ionic strength upon decreasing $\mathrm{pH}$. Surfactant-free polymer latexes are indeed highly sensitive to ionic strength. ${ }^{28}$ The polymerization performed at $\mathrm{pH} 2.2$ in the serum of the IO suspension also resulted in the formation of large particles $\left(D_{\mathrm{h}}=586 \mathrm{~nm}\right.$, run 4, Figure 2a). Interestingly, the particle size was not significantly influenced by the presence of IO in the absence of MAA: $D_{\mathrm{h}}=451 \mathrm{~nm}$ (run 5) versus $420 \mathrm{~nm}$ (run 1), indicating that pristine IO was not capable to act as a Pickering stabilizer as confirmed by the cryo-TEM image of Figure $2 \mathrm{~b}$. It was only when IO and MAA were used together that significantly smaller polymer latex particles $\left(D_{\mathrm{h}}=260 \mathrm{~nm}\right.$, run 6) could be successfully obtained. The cryo-TEM image of Figure $2 \mathrm{c}$ shows however that only a small fraction of IO nanoparticles was located at the polymer surface at the end of the reaction. Indeed, a few IO clusters could be occasionally seen around the particles but the majority of the magnetic particles were remaining free in the water phase. This was also reflected in the low IO incorporation efficiency $(I E)$ and the latex surface coverage by IO (Cov), as only approximately $20 \mathrm{wt} \%$ of the IO particles were actually adsorbed on the 
PMMA latex particles as determined by TGA, which corresponds to approximately $5 \%$ coverage (Table 1). It is thus surprising that such a small amount of IO, unevenly distributed on the particle surface, contributes to a significant decrease of the particle size as observed experimentally. We will come back to this point later on in the discussion.
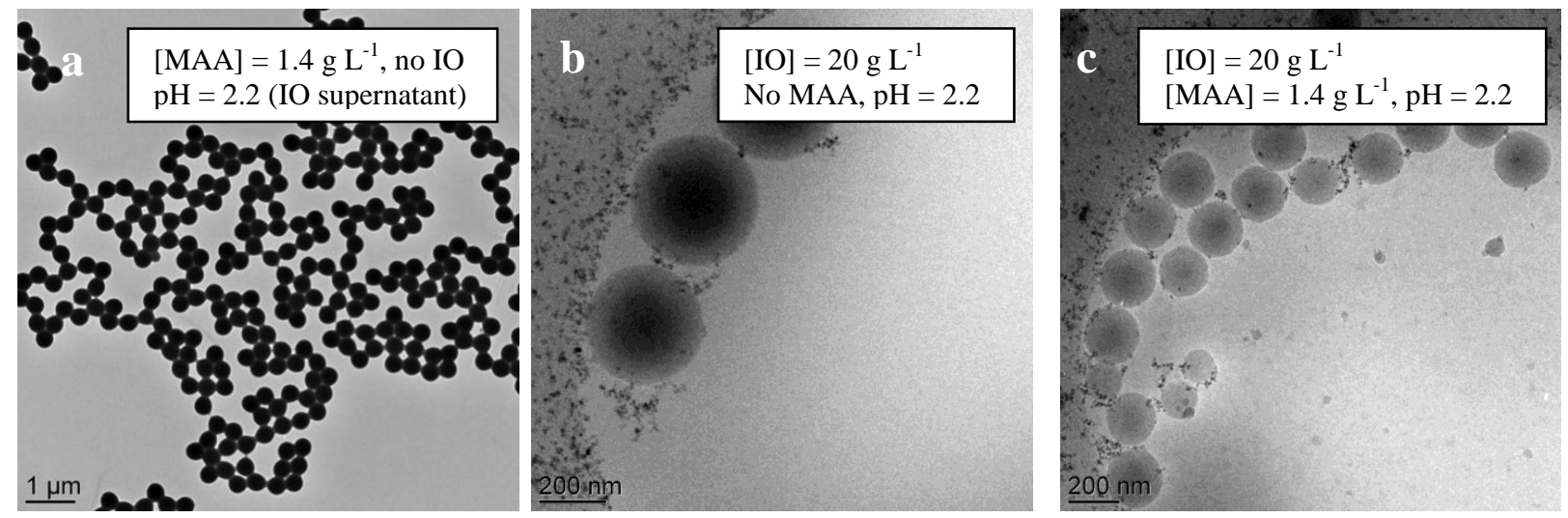

Figure 2. Cryo-TEM images of PMMA latex particles synthesized in the presence of: a) MAA alone (1.4 $\mathrm{g} \mathrm{L}^{-1}$, run 4), b) IO alone (20 $\mathrm{g} \mathrm{L}^{-1}$, run 5), and c) both IO (20 $\left.\mathrm{g} \mathrm{L}^{-1}\right)$ and MAA (1.4 $\mathrm{g} \mathrm{L}^{-1}$, i.e. $5 \mu \mathrm{mol} \mathrm{m} \mathrm{m}^{-2}$, run 6). All experiments were carried out at $70{ }^{\circ} \mathrm{C}$ with MMA: $20 \mathrm{wt} \% /$ water and ADIBA: $1 \mathrm{wt} \% /$ MMA.

Figure 3 shows the evolution of conversion with time and of the particle size and particle number with conversion for this first series of experiments. The rates of the polymerizations performed in the presence of MAA (runs 2, 3, 4 and 6) are very high with $100 \%$ conversion being achieved in less than 30 minutes.

According to Fitch, ${ }^{29}$ the nucleation rate in surfactant-free emulsion polymerization strongly depends on the events taking place in water and notably on the rate of aqueous phase polymerization, which in turns depends on the monomer(s) concentration in water and on the propagation rate constants. The addition of MAA increases the total monomer concentration in water, which increases the rate of oligoradicals formation. This in turns increases the 
number of reaction loci, which increases the polymerization rate. Indeed, the polymerization rate was significantly higher when the polymerization was performed in the presence of MAA than when no MAA was introduced in the solution (Figure 3a). The reaction rate also appears to be influenced by the presence of IO and decreases in both cases (with or without MAA) although it is again higher in the presence of MAA. The particle size, and hence the particle number were also strongly influenced by the presence of IO suggesting a different nucleation mechanism (Figures $3 b$ and $3 c$ ). In the absence of IO, the particle number was fixed very early and did not significantly evolve during polymerization. In the presence of IO, the nucleation stage showed on the contrary a limited aggregation (i.e. the particle number decreased). The aggregation rate was more important in the presence of MAA, which is likely due to the fact that a greater number of particles have been formed initially. The final number of latex particles $\left(1.710^{17} \mathrm{~L}^{-1}\right)$ remained however two orders of magnitude higher than in the absence of MAA $\left(3.610^{15} \mathrm{~L}^{-1}\right)$ pointing again to the determinant role of the IO nanoparticles on nucleation.

In summary, the capability of $\gamma-\mathrm{Fe}_{2} \mathrm{O}_{3}$ nanoparticles to act as a Pickering stabilizer during the emulsion polymerization of MMA using MAA as auxiliary comonomer was demonstrated in these preliminary experiments. However, the low IO incorporation efficiency and the low affinity of the IO nanoparticles for the PMMA surface (as evidenced by TGA and TEM analyses), raise concerns about the underlying particle formation mechanism. Therefore, the adsorption properties of MAA onto IO were investigated in the following section to address this issue. 
a

Conv.

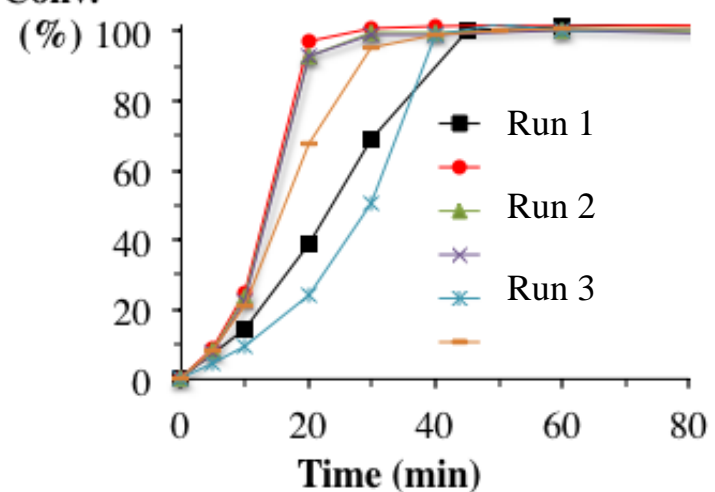

b



c

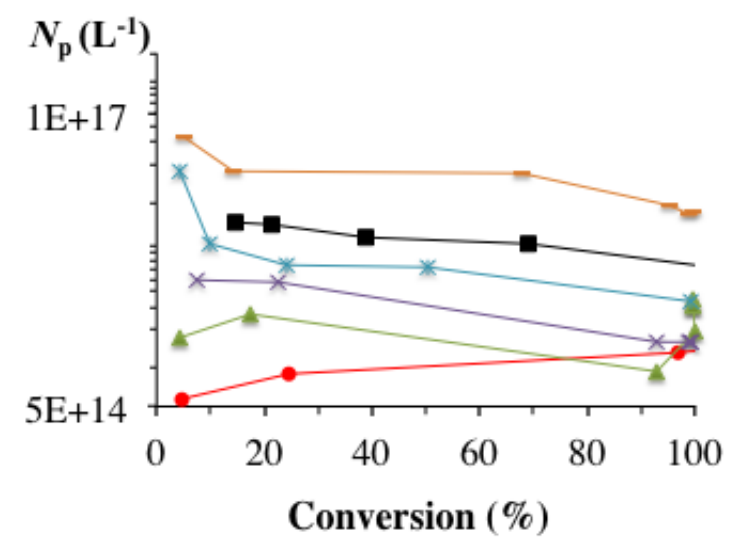

Figure 3. Evolution of: a) conversion versus time, b) particle diameter versus conversion, and c) particle number versus conversion for a series of preliminary surfactant-free emulsion polymerization experiments performed in the absence of IO and MAA (run 1), in the absence of IO with $1.4 \mathrm{~g} \mathrm{~L}^{-1}$ MAA under different $\mathrm{pH}$ conditions: $\mathrm{pH}=3.1$ (run 2), $\mathrm{pH}=2.2$ (adjusted with $\mathrm{HNO}_{3}$ ) (run 3), $\mathrm{pH}=2.2$ (continuous phase of IO) (run 4), and in the presence of $20 \mathrm{~g} \mathrm{~L}^{-1} \mathrm{IO}$ without MAA (run 5) or with $1.4 \mathrm{~g} \mathrm{~L}^{-1}$ MAA (i.e. $5 \mu \mathrm{mol} \mathrm{m}{ }^{-2}$ ) (run 6). All experiments were carried out at $70{ }^{\circ} \mathrm{C}$ with MMA: $20 \mathrm{wt} \% /$ water and ADIBA: $1 \mathrm{wt} \% / \mathrm{MMA}$. 


\section{MAA adsorption onto IO nanoparticles}

The adsorption isotherms of MAA onto IO nanoparticles at $\mathrm{pH} 2.2$ and 4.5 are shown in Figure 4. In both cases, MAA adsorption steadily increased with increasing solution concentration until a plateau was reached for an equilibrium concentration of around $12 \mathrm{~g} \mathrm{~L}^{-1}$. The plateau adsorption at $\mathrm{pH} 4.5\left(5 \mathrm{mg} \mathrm{g}^{-1}\right.$ or $\left.0.35 \mu \mathrm{mol} \mathrm{m} \mathrm{m}^{-2}\right)$ was almost two times higher than that at $\mathrm{pH} 2.2\left(3 \mathrm{mg} \mathrm{g}^{-1}\right.$ or $\left.0.23 \mu \mathrm{mol} \mathrm{m}^{-2}\right)$.

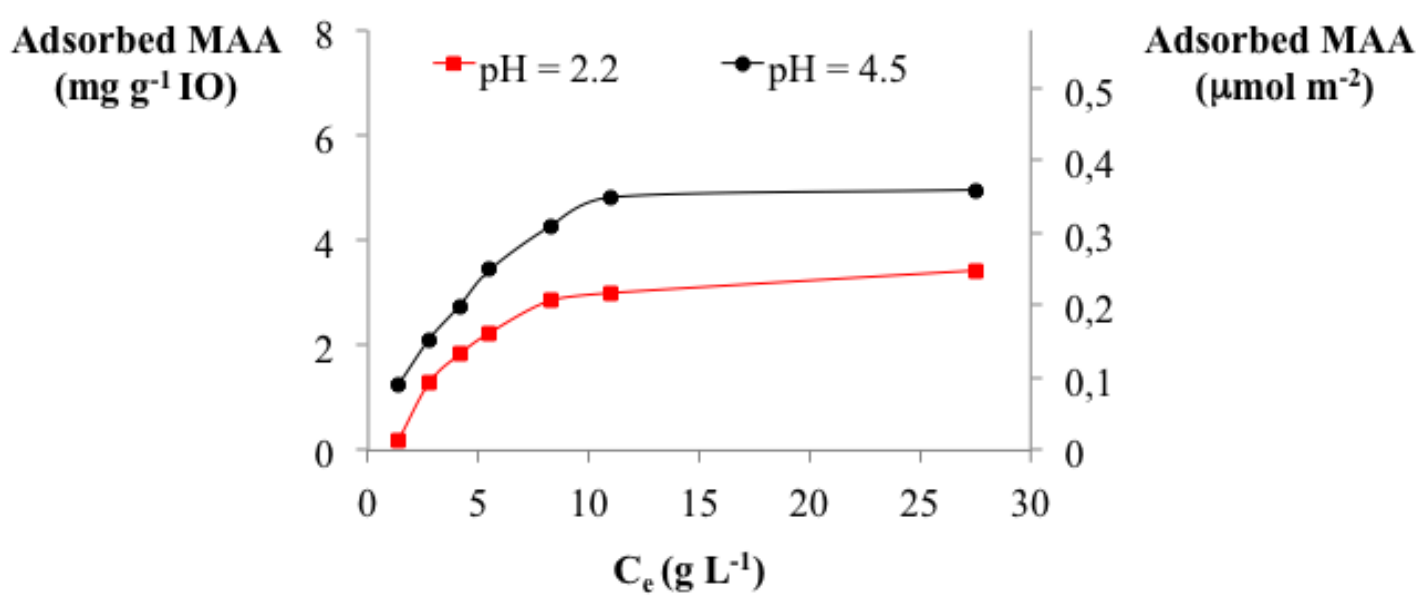

Figure 4. Evolution of the adsorbed amount of MAA ( $\mathrm{mg} \mathrm{g}^{-1}$, left or $\mu \mathrm{mol} \mathrm{m}{ }^{-2}$, right) on the IO surface at $\mathrm{pH} 2.2$ and $\mathrm{pH} 4.5$ as a function of the residual (equilibrium) MAA concentration in water, $\mathrm{C}_{\mathrm{e}}$. $[\mathrm{IO}]=20 \mathrm{~g} \mathrm{~L}^{-1}$.

Hwang et al. ${ }^{25,30}$ studied the adsorption of a series of C4-dicarboxylic acids (maleic, fumaric and succinic acids) at the hematite $\left(\alpha-\mathrm{Fe}_{2} \mathrm{O}_{3}\right)$ /water interface, and showed that the adsorption was $\mathrm{pH}$-dependent. The adsorption increased with increasing $\mathrm{pH}$ up to the $\mathrm{pKa}$ of the acid and then decreased approaching zero at $\mathrm{pH}$ values above the point of zero charge, where both the hematite surface and the organic acid were negatively charged. Based on this result, the authors concluded that electrostatic interaction was the major contribution to the adsorption of organic acids on hematite. Considering that the pKa of MAA is $4.4,{ }^{31,32}$ we also drew the conclusion that an increasing $\mathrm{pH}$ promoted electrostatic interactions. However, the plateau 
adsorption $\left(0.25-0.35 \mu \mathrm{mol} \mathrm{m} \mathrm{m}^{-2}\right)$ was in both cases much lower than the lower maxima

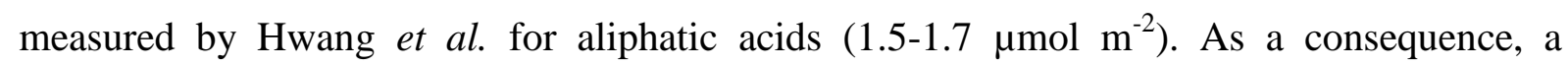
significant amount of MAA remained in solution (around $99 \mathrm{wt} \%$ at the plateau at $\mathrm{pH} 4.5$ ) even for low initial concentrations. Such a low MAA adsorption is surprising as carboxylic acids have been reported to strongly adsorb on transition metal oxides, including iron oxides. $^{25,33,34}$ A possible explanation may lie in the fact that the MAA molecules are not able to efficiently displace the adsorbed nitrate ions, which are present in large concentration in the suspension medium. This hypothesis was verified by FTIR analysis of the MAA/IO complexes which showed the presence of a band at $1385 \mathrm{~cm}^{-1}$ attributed to nitrate vibrations (Figure S1, Supporting Information). ${ }^{35}$ In addition, DLS confirmed that MAA adsorption had no influence on particle size and $\zeta$ potential, which both remained constant over the full range of MAA concentrations investigated for the two $\mathrm{pH}$ values (Figure S3 in the Supporting Information). These results are consistent with the adsorption isotherms, and show that the MAA molecules, which are adsorbed in only small quantities, do not affect the IO surface charge and colloidal stability.

\section{Effect of MAA and IO concentrations}

The above adsorption experiments showed an unexpected weak interaction between MAA and IO, which can account for the low IO incorporation efficiency and the low latex surface coverage by IO. However, based on the DLS results, MAA obviously plays a key role in particle nucleation in the presence of IO by decreasing the particle size by a factor of two and by influencing the polymerization kinetics (Figures $3 \mathrm{~b}$ and $3 \mathrm{a}$, respectively). As most of MAA is initially located in water, one must consider the oligomers they form in the aqueous phase upon reaction with solubilized MMA. Such P(MAA-co-MMA) copolymer entities may likely adsorb on the IO surface more strongly than the corresponding monomer molecules due 
to the multiplicity of anchoring groups in the whole polymer chains, even if the affinity of each individual repeat unit for the particle surface is low. The composition of these oligomers depends on the relative concentration and reactivity ratios of the different monomers present in the aqueous phase. In general, the reactivity of ionizable monomers is strongly influenced by the nature of the medium (notably its polarity and proton donor or proton acceptor abilities), ${ }^{36}$ and by the degree of dissociation of the ionic groups (and so by the $\mathrm{pH}$ ). There is to our knowledge only two articles reporting the reactivity ratios of MAA (monomer 1) with MMA (monomer 2) in water. ${ }^{37,38}$ In Bezuglyi et al., ${ }^{37}$ the reactivity ratios were reported to be $r_{1}=0.43$ and $r_{2}=2.61$ while Daswani et al. ${ }^{38}$ used the chemical composition of the very short oligomers formed at very low conversions during surfactant-free emulsion copolymerization (as determined by MALDI-ToF MS analysis), and estimated the apparent reactivity ratios to be $r_{1}=2.74$ and $r_{2}=3.99$ at chain length 6 . Note that these values are very different from reactivity ratios reported in bulk. ${ }^{39}$ Furthermore, under our experimental conditions, the water phase initially contains more MMA than MAA as determined from the MMA solubility in water $\left(15.9 \mathrm{~g} \mathrm{~L}^{-1}\right.$ at $\left.20{ }^{\circ} \mathrm{C}\right)$ and the MAA concentration $\left(1.4 \mathrm{~g} \mathrm{~L}^{-1}\right.$, run 6, Table 1). Therefore, given the estimated reactivity ratios and the high MMA concentration in water (compared to that of MAA), the oligomers formed at very low conversion are likely MMA-rich, which may account for the low IO incorporation efficiency and the low latex surface coverage by IO. In the following series of experiments, the amount of MAA was thus gradually increased with the aim of improving IO adhesion to the particle surface, and consequently increase the IO incorporation efficiency at $\mathrm{pH} 2.2$ (runs 6 and 10-12 in Table 2). In order to properly assess the role of MAA, control experiments were first conducted in the absence of IO under otherwise exactly the same experimental conditions as in the presence of IO (runs 2 and 7-9 in Table 2). When the MAA concentration was varied from 1.4 to $8.4 \mathrm{~g} \mathrm{~L}^{-1}$ (which is equivalent to $5-30 \mu \mathrm{mol} \mathrm{m} \mathrm{m}^{-2}$ in the $\mathrm{IO}$ experiments) for $\mathrm{pH}$ values comprised between 2.6 and 3.1 , the 
DLS results showed that the particle size increased from approximately 470 to $720 \mathrm{~nm}$ (runs 2, 7 and 8, Table 2). A further increase in MAA concentration (11.2 $\mathrm{g} \mathrm{L}^{-1}$, run 9) led to latex destabilization. The evolution of monomer conversion with time showed that the reaction rate was not significantly influenced by the MAA concentration (Figure S4 in the Supporting Information). The initial reaction rate was however slightly higher as increasing the MAA concentration increases the concentration of water-soluble oligomers, and hence the nucleation rate. This resulted in the formation of a large number of unstable primary particles that aggregated to form stable mature particles. The higher the number of primary particles, the higher the probability of collision, and the larger was consequently the final particle size. The particle size therefore increased with increasing MAA concentration while the reaction rate was not really affected due to the two opposing effects (initial increase in rate due to enhanced particle nucleation and further decrease in rate due to limited flocculation).

Table 2. Effect of MAA concentration on the surfactant-free emulsion polymerization of MMA in the absence and in the presence of increasing amounts of $\mathrm{IO}$ at $\mathrm{pH}$ around 2.2. ${ }^{a}$

\begin{tabular}{|c|c|c|c|c|c|c|c|c|c|c|}
\hline Run & $\underset{\left(g^{\mathbf{I O}} \mathbf{L}^{-1}\right)}{\mathbf{I}}$ & $\begin{array}{l}\text { MAA } \\
\left(g_{\text { L L }}^{-1}\right)\end{array}$ & $\underset{\left(\mu \mathrm{mol} \mathrm{m} \mathbf{~ m}^{-2}\right)}{\operatorname{MAA}}$ & $\mathrm{pH}_{\mathrm{i}}{ }^{b}$ & $\begin{array}{c}\text { Conv. } \\
(\%)\end{array}$ & $\underset{(\mathbf{n m})}{D_{\mathbf{h}}}$ & Poly $^{c}$ & $N_{\mathrm{p}}\left(\mathbf{L}^{-1}\right)^{d}$ & $\begin{array}{l}I E \\
(\%)^{e}\end{array}$ & $\begin{array}{l}\text { Cov } \\
(\%)^{f}\end{array}$ \\
\hline 2 & 0 & 1.4 & I & 3.1 & 100 & 473 & 0.07 & $3.110^{15}$ & I & I \\
\hline 7 & 0 & 2.8 & / & 2.9 & 100 & 513 & 0.09 & $2.410^{15}$ & I & / \\
\hline 8 & 0 & 8.4 & I & 2.7 & 100 & 724 & 0.12 & $8.510^{14}$ & I & / \\
\hline $9^{g}$ & 0 & 11.2 & I & 2.6 & $29^{h}$ & $443^{h}$ & 0.18 & $1.110^{15}$ & I & I \\
\hline 6 & 20 & 1.4 & 5 & 2.2 & 99 & 267 & 0.04 & $1.710^{16}$ & 20.4 & 5.5 \\
\hline 10 & 20 & 2.8 & 10 & 2.2 & 98 & 243 & 0.04 & $2.210^{16}$ & 26.2 & 6.5 \\
\hline 11 & 20 & 8.4 & 30 & 2.2 & 98 & 191 & 0.04 & $4.610^{16}$ & 71.8 & 13.8 \\
\hline $12^{g}$ & 20 & 11.2 & 40 & 2.2 & $49^{h}$ & $143^{h}$ & 0.11 & I & I & / \\
\hline 13 & 10 & 0.7 & 5 & 2.2 & 100 & 278 & 0.02 & $1.510^{16}$ & 22.1 & 3.1 \\
\hline 14 & 30 & 2.1 & 5 & 2.2 & 100 & 223 & 0.09 & $2.910^{16}$ & 31.4 & 10.6 \\
\hline $15^{g}$ & 40 & 2.8 & 5 & 2.2 & $46^{h}$ & $219^{h}$ & 0.09 & / & I & / \\
\hline
\end{tabular}


Significantly different results were obtained when the polymerization was performed in the presence of IO (runs 6 and 10-12 in Table 2). Contrary to the control experiments where we observed an increase in particle size and a constant polymerization rate, the particle size decreased from 267 to $191 \mathrm{~nm}$ with increasing MAA concentration from 1.4 to $8.4 \mathrm{~g} \mathrm{~L}^{-1}$ and the reaction rate increased concurrently as there were more nucleated particles (Figure 5a). The latex was again destabilized for a too high MAA concentration (run 12) indicating that the IO nanoparticles were not capable to stabilize a too large surface area. The IO incorporation efficiency determined by TGA was found to increase from 20 to around $72 \mathrm{wt} \%$ with increasing MAA concentration from 5 to $30 \mu \mathrm{mol} \mathrm{m} \mathrm{m}^{-2}$ while the surface coverage increased by only $10 \%$ due to the concomitant decrease in particle size resulting in a higher total particle surface area.

The electron microscopy images of Figure 6 confirmed qualitatively that the amount of free IO in water decreased with increasing MAA concentration and that there were apparently more IO particles on the polymer surface in run $11\left(\mathrm{MAA}=30 \mu \mathrm{mol} \mathrm{m}{ }^{-2}\right)$ than in run 10 $\left(\mathrm{MAA}=10 \mu \mathrm{mol} \mathrm{m} \mathrm{m}^{-2}\right)$. The IO nanoparticles were, however, still not uniformly distributed on the PMMA surface as attested by the cryo-TEM image of Figure 6c.
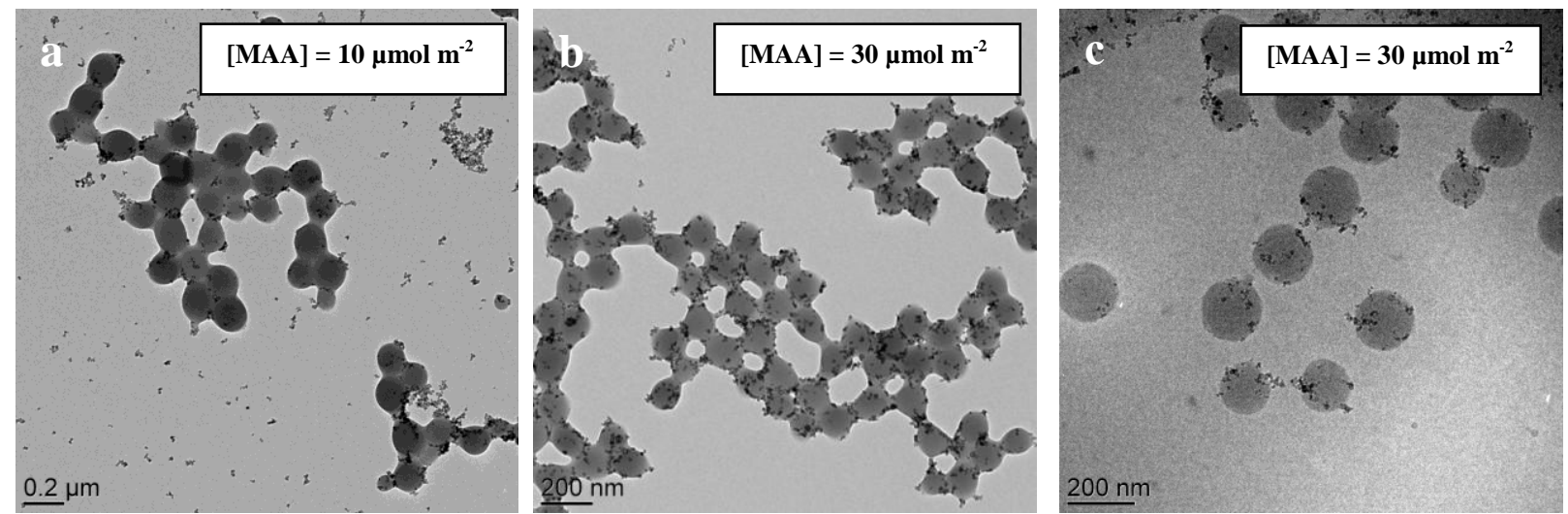

Figure 6. a-b) TEM and c) cryo-TEM images of PMMA latex particles synthesized in the presence of increasing MAA concentrations. a) run 10: $10 \mu \mathrm{mol} \mathrm{m}{ }^{-2}$ MAA and b, c) run 11: 30 $\mu \mathrm{mol} \mathrm{m}{ }^{-2}$ MAA. All experiments were carried out at $70{ }^{\circ} \mathrm{C}$ with $\mathrm{IO}=20 \mathrm{~g} \mathrm{~L}^{-1}$, MMA: $20 \mathrm{wt}$ $\% /$ water and ADIBA: 1 wt \%/MMA. 
$\mathbf{a}$

Conv.

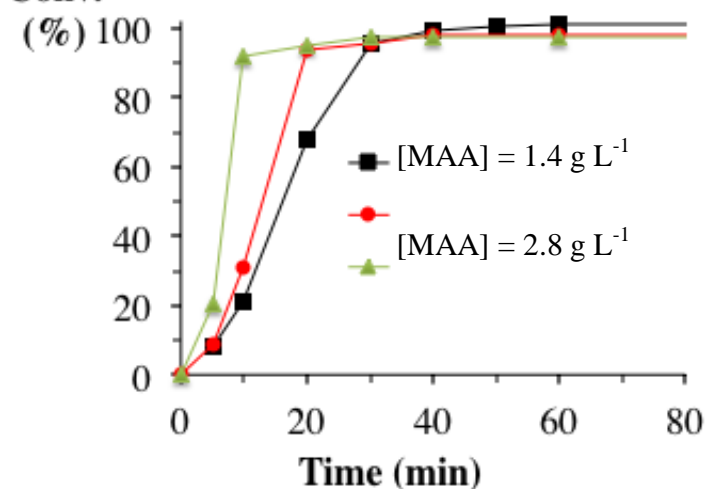

b

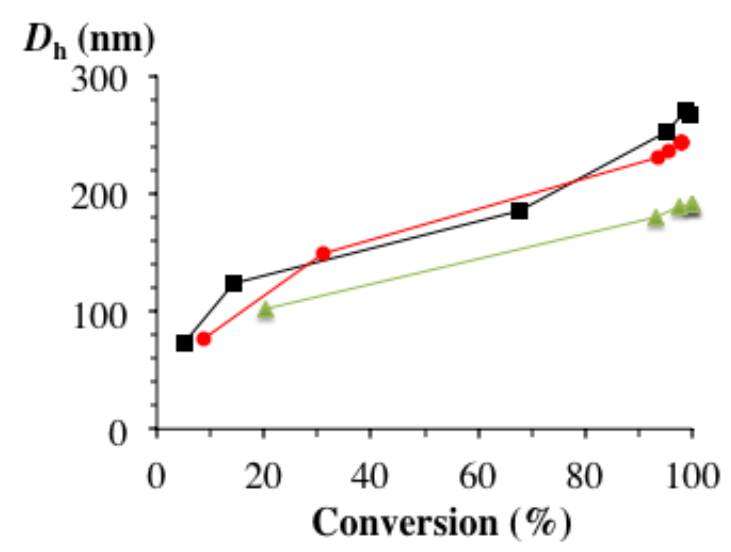

c

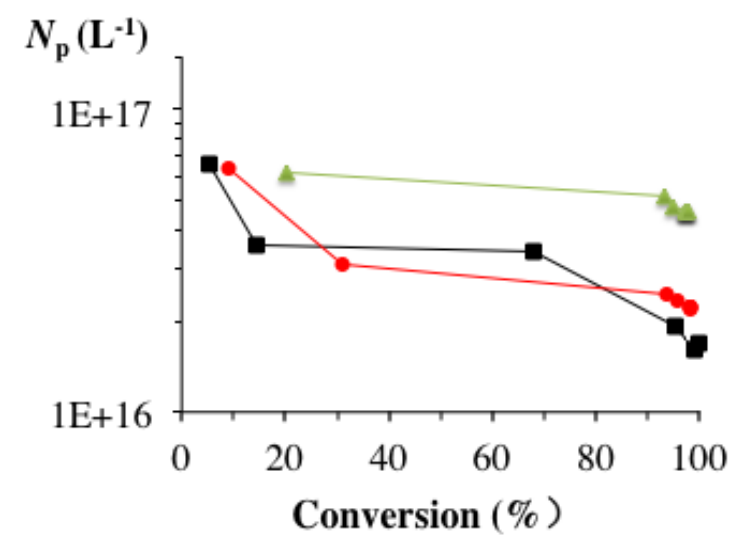

Figure 5. Effect of MAA concentration on the evolution of: a) conversion versus time, b) particle diameter versus conversion, and c) particle number versus conversion for surfactant-free emulsion polymerizations of MMA performed in the presence of $20 \mathrm{~g} \mathrm{~L}^{-1} \mathrm{IO}_{\text {. }}\left[\mathrm{MAA}\right.$ ] $=1.4 \mathrm{~g} \mathrm{~L}{ }^{-1}$ (run 6), $[\mathrm{MAA}]=2.8 \mathrm{~g} \mathrm{~L}^{-1}$ (run 10) and $[\mathrm{MAA}]=8.4 \mathrm{~g} \mathrm{~L}^{-1}$ (run 11). All experiments were carried out at $70{ }^{\circ} \mathrm{C}$ with $\mathrm{MMA}: 20 \mathrm{wt} \% / \mathrm{water}$ and ADIBA: 1 wt \%/MMA. 
As mentioned above, the IO nanoparticles can likely be attached to the PMMA surface thanks to the multiplicity of anchoring groups in the whole polymer chain. Increasing MAA concentration promotes MAA incorporation into the chains, which would favor the adsorption of the IO nanoparticles on the latex surface. However, on the other hand, MAA-rich oligomers may also promote IO particles aggregation in water, resulting in the formation of chain-like IO nanoclusters. Such a clustering mechanism could account for the nonuniformity of the surface coverage. With the aim to further improve the IO incorporation efficiency, in the next series of experiments, the IO concentration was increased from 10 to 40 $\mathrm{g} \mathrm{L}^{-1}$ while maintaining a constant MAA concentration of $5 \mu \mathrm{mol} \mathrm{m}{ }^{-2}$ (runs $6,13,14$ and 15 in Table 2). Note that the total MAA concentration also increased with increasing IO content, which could favor the formation of MAA-richer copolymer chains, and promote consequently IO incorporation into the polymer latex particles. Figure 7 shows the evolution of conversion with time and of particle diameter and particle number with conversion for this series of experiments. There is a significant influence of the initial amount of IO on kinetics (Figure 7a). The reaction rate increased with increasing IO (and thus MAA) contents from 10 to $30 \mathrm{~g}$ $\mathrm{L}^{-1}$ (runs 13, 6 and 14 in Table 2) while the particle size decreased from 280 to $223 \mathrm{~nm}$ (Figure $7 \mathrm{~b}$ ). This suggests that the incorporation of more MAA in the oligomers promotes IO adhesion to the particles surface, and consequently increases latex stability. The increase in the reaction rate with increasing IO content can therefore be mainly attributed to the increase in the number of particles. TEM analysis revealed, however, that only a few IO nanoparticles were located on the polymer surface, most of them being located in the continuous phase (see Figure S5 in the Supporting Information) as confirmed by the low $I E$ values, close to $20 \mathrm{wt} \%$ for 10 and $20 \mathrm{~g} \mathrm{~L}^{-1}$ of IO. IE nevertheless increased to $31.4 \mathrm{wt} \%$ when the IO concentration was increased to $30 \mathrm{~g} \mathrm{~L}^{-1}$. However, when the IO concentration was increased further to $40 \mathrm{~g}$ $\mathrm{L}^{-1}$, the latex became unstable (run 15). 
a

Conv.

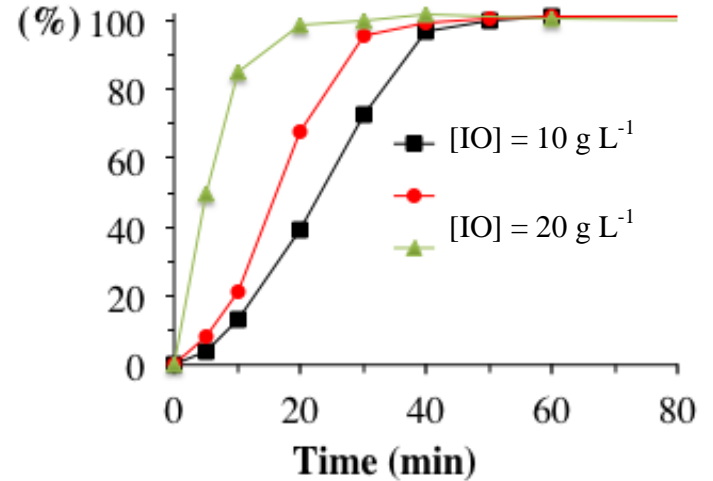

b

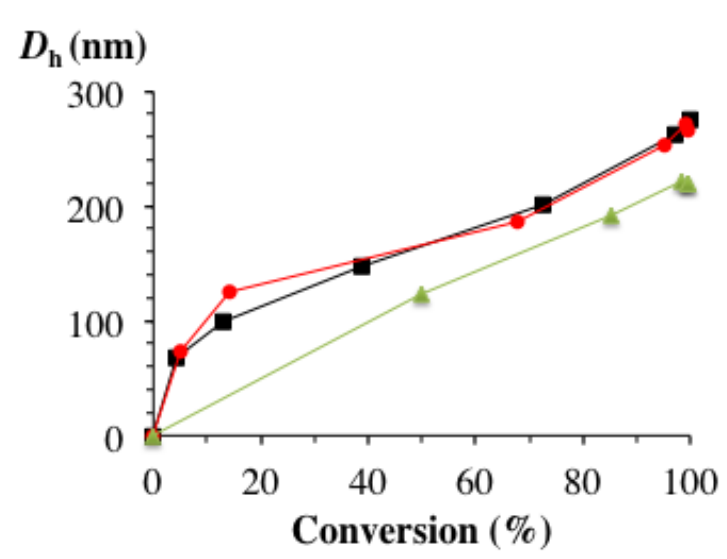

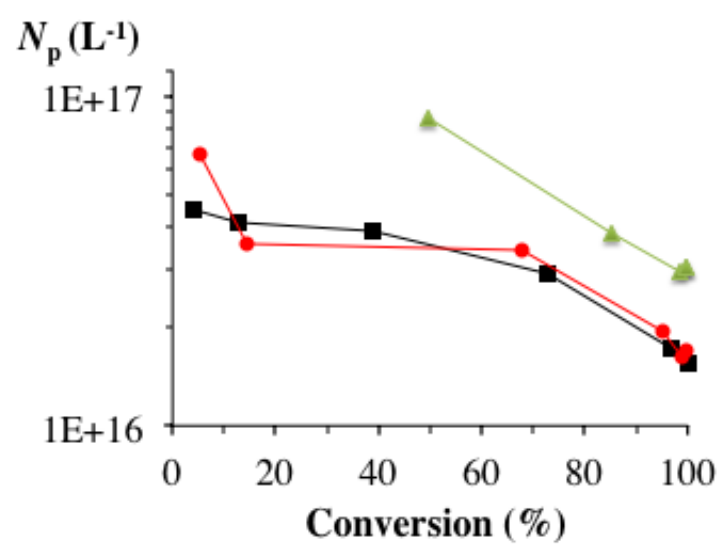

Figure 7. Effect of IO concentration on the evolution of: a) conversion versus time, b) particle diameter versus conversion, and c) particle number versus conversion for surfactant-free emulsion polymerizations of MMA performed in the presence of $5 \mu$ mol $\mathrm{m}^{-2} \mathrm{MAA}$ at $\mathrm{pH} 2.2$. [IO] $=10 \mathrm{~g} \mathrm{~L}^{-1}$ (run 13), $[\mathrm{IO}]=20 \mathrm{~g} \mathrm{~L}^{-1}$ (run 6) and $[\mathrm{IO}]=30 \mathrm{~g} \mathrm{~L}^{-1}$ (run 14). All experiments were carried out at $70{ }^{\circ} \mathrm{C}$ with $\mathrm{MMA}: 20 \mathrm{wt} \% / \mathrm{water}$ and ADIBA: 1 wt \%/MMA. 


\section{Effect of suspension $\mathrm{pH}$}

In this section, we studied the effect of the suspension $\mathrm{pH}$ with the objective of getting better MAA/IO interactions, and increase consequently the particle surface coverage and the IO incorporation efficiency. The IO suspension was dialyzed until $\mathrm{pH} 3.3$ or 4.5 and the IO content was fixed to $20 \mathrm{~g} \mathrm{~L}^{-1}$ in order to compare these experiments with the previous ones carried out at $\mathrm{pH} 2.2$ (Table 3 ).

Table 3. Summary of experimental conditions and results of surfactant-free emulsion polymerizations of MMA for increasing $\mathrm{pH}$ values in the presence of $20 \mathrm{~g} \mathrm{~L}^{-1}$ IO and $5 \mu \mathrm{mol}$ $\mathrm{m}^{-2}$ of MAA (i.e. $\left.1.4 \mathrm{~g} \mathrm{~L}^{-1}\right)^{a}$

\begin{tabular}{|c|c|c|c|c|c|c|c|c|c|c|}
\hline Run & $\underset{\left(g^{-1} \mathbf{L}^{-1}\right)}{\mathbf{I O}}$ & $\begin{array}{c}\text { MAA } \\
\left(\mathbf{g ~ L}^{-1}\right)\end{array}$ & $\underset{\left(\mu \mathrm{mol} \mathrm{\mathbf { } ^ { - 2 }}\right)}{\operatorname{MAA}}$ & $\mathbf{p H}_{\mathbf{i}}{ }^{b}$ & $\begin{array}{c}\text { Conv. } \\
(\%)\end{array}$ & $\begin{array}{c}D_{\mathbf{h}} \\
(\mathbf{n m})^{c}\end{array}$ & Poly $^{c}$ & $N_{\mathrm{p}}\left(\mathrm{L}^{-1}\right)^{d}$ & $\begin{array}{c}I \boldsymbol{E} \\
(\%)^{e}\end{array}$ & $\begin{array}{l}\text { Cov } \\
(\%)^{f}\end{array}$ \\
\hline 6 & 20 & 1.4 & 5 & 2.2 & 99 & 267 & 0.04 & $1.710^{16}$ & 20.4 & 5.5 \\
\hline 16 & 20 & 1.4 & 5 & 3.3 & 100 & 242 & 0.08 & $2.310^{16}$ & 32.4 & 7.9 \\
\hline 17 & 20 & 1.4 & 5 & 4.5 & 100 & 218 & 0.12 & $3.210^{16}$ & 50.4 & 11.0 \\
\hline 18 & 40 & 2.8 & 5 & 4.5 & 96 & 207 & 0.11 & $3.610^{16}$ & 58.8 & 25.5 \\
\hline 19 & 60 & 4.1 & 5 & 4.5 & 95 & 190 & 0.10 & $4.710^{16}$ & 60.2 & 36.3 \\
\hline $20^{g}$ & 70 & 4.8 & 5 & 4.5 & $58^{h}$ & $165^{h}$ & 0.11 & / & I & I \\
\hline
\end{tabular}

${ }^{a}$ All experiments were carried out for $2 \mathrm{~h}$ with MMA $=20 \mathrm{wt} \% /$ water, ADIBA $=1 \mathrm{wt} \% / \mathrm{MMA}$ and $\mathrm{T}=70{ }^{\circ} \mathrm{C},{ }^{b}$ $\mathrm{pH}$ value of the IO suspension, adjusted to 3.3 or 4.5 by dialysis. ${ }^{c}$ Determined by DLS. ${ }^{d}$ Calculated using equation (7). ${ }^{e}$ Calculated using equation (4). ${ }^{f}$ Calculated using equation $(5) .{ }^{g}$ Latex destabilization after 10 minutes. ${ }^{h}$ Monomer conversion and particle size determined just before latex destabilization.

The experiments performed using $5 \mu \mathrm{mol} \mathrm{m} \mathrm{m}^{-2}$ of MAA (runs 6, 16 and 17, Table 3) resulted in the formation of stable latexes for all $\mathrm{pH}$ values. With increasing $\mathrm{pH}$ from 2.2 to 4.5 , the particle size decreased from $267 \mathrm{~nm}$ to $218 \mathrm{~nm}$ while the reaction rate increased due to the increased number of reaction loci (Figure 8). The IO particles still appeared to be unevenly distributed around the PMMA particles forming in all cases a "patchy" iron oxide overlayer (Figure 9). 
a

Conv.

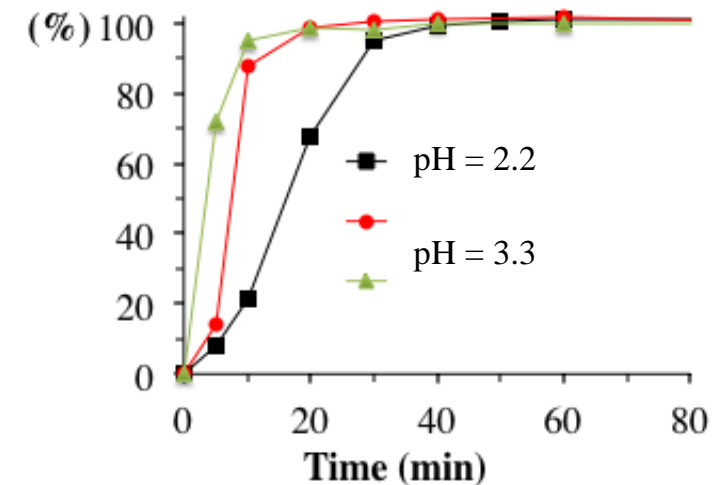

b

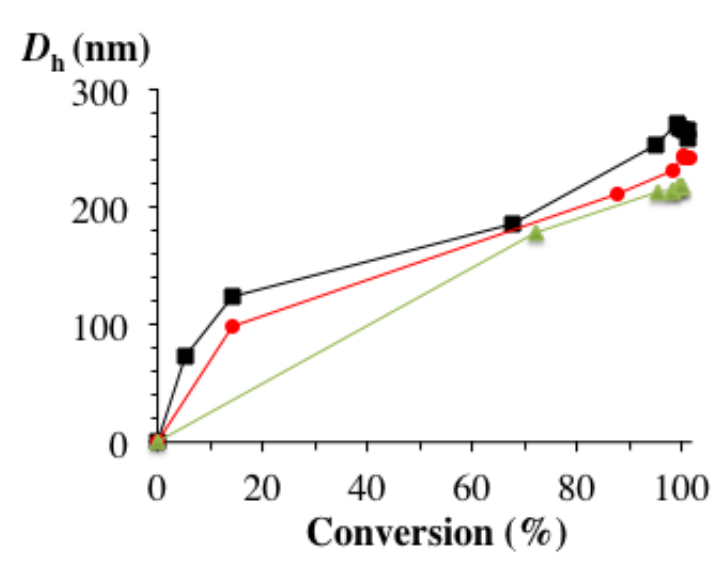

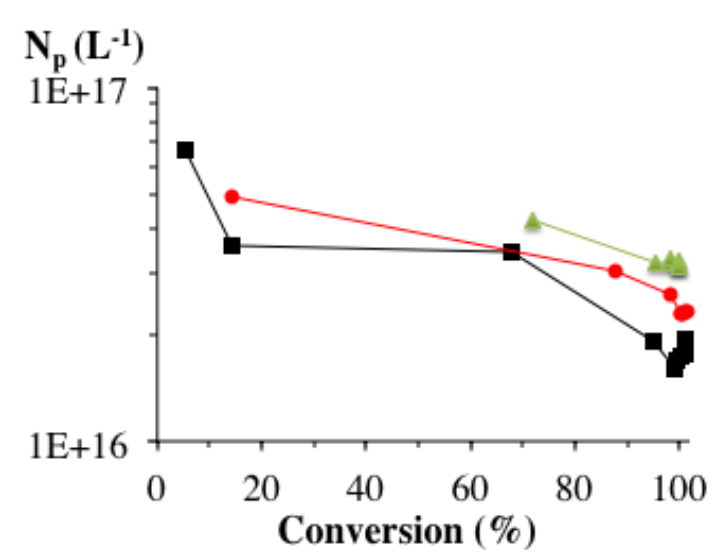

Figure 8. Effect of $\mathrm{pH}$ on the evolution of: a) conversion versus time, b) particle diameter versus conversion, and c) particle number versus conversion for surfactant-free emulsion polymerizations of MMA performed in the presence of $20 \mathrm{~g} \mathrm{~L}^{-1} \mathrm{IO}$ and $5 \mu \mathrm{mol} \mathrm{m}{ }^{-2} \mathrm{MAA}$. $\mathrm{pH}=2.2$ (run 6 ), $\mathrm{pH}=3.3$ (run 16) and $\mathrm{pH}=4.5$ (run 17). All experiments were carried out at $70{ }^{\circ} \mathrm{C}$ with MMA: 20 wt $\% /$ water and ADIBA: 1 wt $\% / \mathrm{MMA}$. 
In addition, TEM analysis also suggests that the amount of free IO is less important in the experiment performed at $\mathrm{pH} 4.5$ (run 17) than in those carried out at lower $\mathrm{pH}$ (i.e. $\mathrm{pH} 2.2$, run 6 and $\mathrm{pH} 3.3$, run 16, respectively). The IO incorporation efficiency indeed reached 50 $\mathrm{wt} \%$ at $\mathrm{pH} 4.5$ while the surface coverage increased to $11 \%$. This result is in good agreement with the adsorption isotherms, which showed stronger interaction between MAA and IO at $\mathrm{pH} 4.5$ than at $\mathrm{pH} 2.2$.
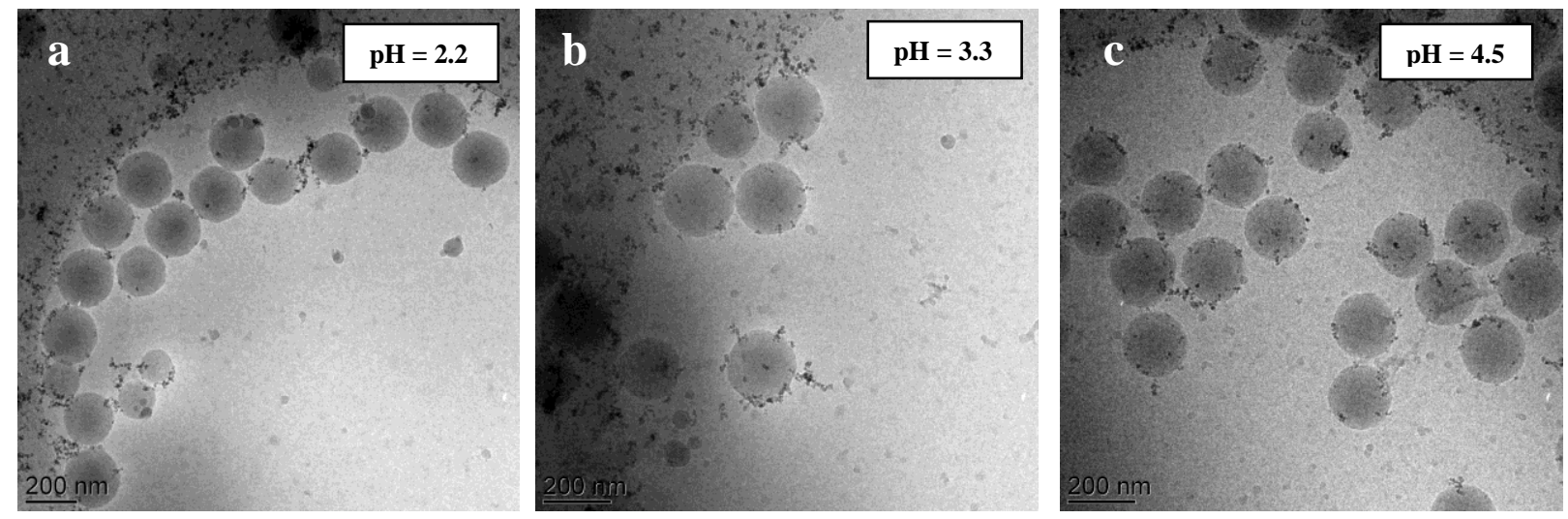

Figure 9. Cryo-TEM images of PMMA latex particles synthesized in the presence of IO for increasing $\mathrm{pH}$ values. a) $\mathrm{pH}=2.2$ (run 6), b) $\mathrm{pH}=3.3$ (run 16), and c) $\mathrm{pH}=4.5$ (run 17). All experiments were carried out at $70{ }^{\circ} \mathrm{C}$ with $\mathrm{IO}=20 \mathrm{~g} \mathrm{~L}^{-1}, \mathrm{MAA}=5 \mu \mathrm{mol} \mathrm{m}{ }^{-2}$, MMA: $20 \mathrm{wt}$ $\% /$ water, ADIBA: $1 \mathrm{wt} \% / \mathrm{MMA}$ and $\mathrm{T}=70{ }^{\circ} \mathrm{C}$.

Increasing IO content at $\mathrm{pH} 4.5$ for a fixed MAA surface concentration of $5 \mu \mathrm{mol} \mathrm{m} \mathrm{m}^{-2}$ (runs 17-20 in Table 3) still had no significant influence on the particle morphology (Figure S6, Supporting Information) and the incorporation efficiency, which increased by only approximately $25 \%$ with increasing the IO concentration from 20 to $60 \mathrm{~g} \mathrm{~L}^{-1}$. However, working at a higher $\mathrm{pH}$ enabled to maintain colloidal stability for higher initial IO contents (up to $60 \mathrm{~g} \mathrm{~L}^{-1}$ at $\mathrm{pH} 4.5$ versus $30 \mathrm{~g} \mathrm{~L}^{-1}$ at $\mathrm{pH} 2.2$ ), which consequently enabled to achieve a higher surface coverage ( $36 \%$ for run 19 compared to $10 \%$ in the best case at pH 2.2 (see run 14, Table 2). 


\section{Effect of the nature of the monomer}

Previous studies on Pickering emulsion polymerization showed that the nature of the hydrophobic monomer played a key role on the size and the stability of the final armored particles. ${ }^{24,40,41,42}$ In order to assess the effect of the nature of the monomer on the incorporation efficiency and particle morphology, two emulsion polymerization experiments were first conducted in the presence of $20 \mathrm{~g} \mathrm{~L}^{-1}$ of IO using BA or St as monomers and 5 $\mu \mathrm{mol} \mathrm{m} \mathrm{m}^{-2}$ of MAA as auxiliary comonomer (runs 21 and 23, Table 4). In order to avoid the dialysis step and compare with the previous series of experiments, the $\mathrm{pH}$ was fixed at 2.2. In all cases, the obtained latexes showed no sign of destabilization.

Table 4. Summary of experimental conditions and results of surfactant-free emulsion polymerizations of MMA, BA or St in the presence of $20 \mathrm{~g} \mathrm{~L}^{-1}$ IO for increasing amounts of MAA at $\mathrm{pH} 2.2^{a}$

\begin{tabular}{cccccccccc}
\hline Run & Monomer & $\begin{array}{c}\text { MAA } \\
\left(\mathbf{g ~ L}^{-1}\right)\end{array}$ & $\begin{array}{c}\text { MAA } \\
\left(\boldsymbol{\mu m o l ~ \mathbf { m } ^ { - 2 }}\right)\end{array}$ & $\begin{array}{c}\text { Conv. } \\
(\boldsymbol{\%})\end{array}$ & $\begin{array}{c}\boldsymbol{D}_{\mathbf{h}} \\
(\mathbf{n m})^{b}\end{array}$ & $\boldsymbol{P o l y}^{b}$ & $\boldsymbol{N}_{\mathbf{p}}\left(\mathbf{L}^{-\mathbf{1}}\right)^{\boldsymbol{c}}$ & $\begin{array}{c}\text { IE } \\
(\boldsymbol{\%})^{\boldsymbol{d}}\end{array}$ & $\begin{array}{c}\text { Cov } \\
(\boldsymbol{\%})^{\boldsymbol{e}}\end{array}$ \\
\hline 6 & MMA & 1.4 & 5 & 99 & 267 & 0.04 & $1.710^{16}$ & 20.4 & 5.5 \\
21 & $\mathrm{BA}$ & 1.4 & 5 & 97 & 442 & 0.31 & $4.010^{15}$ & 5.6 & 2.6 \\
$22^{f}$ & $\mathrm{BA}$ & 2.8 & 10 & $93^{h}$ & $392^{h}$ & 0.31 & $/$ & $/$ & $/$ \\
23 & $\mathrm{St}$ & 1.4 & 5 & 94 & 240 & 0.04 & $2.510^{16}$ & 30.6 & 7.7 \\
24 & $\mathrm{St}$ & 2.8 & 10 & 95 & 190 & 0.05 & $5.110^{16}$ & 45.8 & 9.2 \\
25 & $\mathrm{St}$ & 5.6 & 20 & 94 & 171 & 0.05 & $7.010^{16}$ & 77.5 & 14.2 \\
$26^{g}$ & $\mathrm{St}$ & 8.4 & 30 & $19^{h}$ & $132^{h}$ & 0.12 & $/$ & $/$ & $/$ \\
\hline
\end{tabular}

${ }^{a}$ All experiments were carried out for $2 \mathrm{~h}$ with monomer $=20 \mathrm{wt} \% /$ water, ADIBA $=1 \mathrm{wt} \% /$ monomer and T $=70{ }^{\circ} \mathrm{C} .{ }^{b}$ Determined by DLS. ${ }^{c}$ Calculated using equation (7). ${ }^{d}$ Calculated using equation (4). ${ }^{e}$ Calculated using equation $(5) .{ }^{f}$ Latex destabilization after 10 minutes. ${ }^{g}$ Latex destabilization after 40 minutes. ${ }^{h}$ Monomer conversion and particle size determined just before latex destabilization.

From Figure 10, it can be seen that the emulsion polymerization of both MMA and BA in the presence of $\mathrm{IO}$ resulted in less $\mathrm{IO}$ on the polymer surface than for St, as reflected in the $I E$ values which were smaller for these two monomers than for St (Table 4). Furthermore, the particle size was bigger for BA $(442 \mathrm{~nm})$ than for MMA $(267 \mathrm{~nm})$ or St $(240 \mathrm{~nm})$. The 
reaction rate was, however, much lower when St was used, despite a higher particle number (related to a better IO incorporation leading to a smaller particle size) (Figure 11). This is likely related to the much lower solubility of styrene in water compared to MMA $\left(4.310^{-3}\right.$ mol L ${ }^{-1}$ at $50^{\circ} \mathrm{C}$ versus $1.510^{-1} \mathrm{~mol} \mathrm{~L}^{-1}$ for MMA) $)^{43}$ and to its lower propagation rate constant $\left(\mathrm{k}_{\mathrm{p} \text { Styr }}=480 \mathrm{~L} \mathrm{~mol}^{-1} \mathrm{~s}^{-1}\right.$ and $\mathrm{k}_{\mathrm{p} \text { MMA }}=1035 \mathrm{~L} \mathrm{~mol}^{-1} \mathrm{~s}^{-1}$ at $\left.70{ }^{\circ} \mathrm{C}\right) .{ }^{44}$ This series of experiments thus suggests that despite the use of the same auxiliary comonomer (MAA), IO adhesion to the polymer particle surface is mainly governed by the monomer nature.
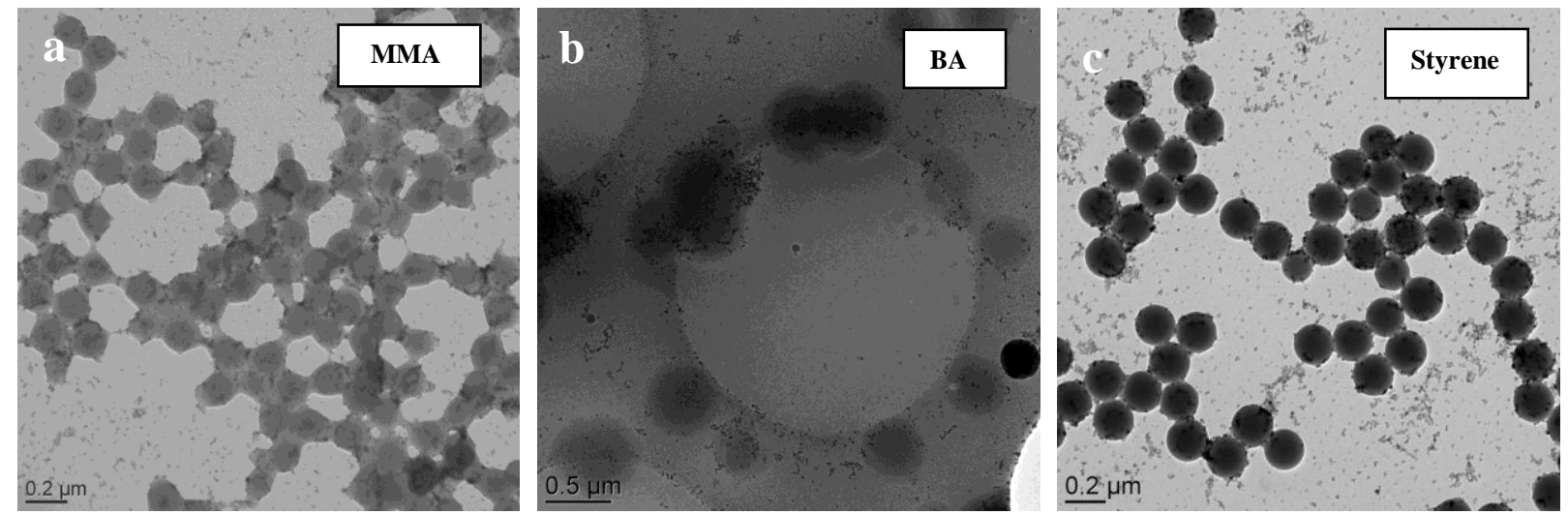

Figure 10. TEM images of polymer/IO composite latex particles synthesized with different monomers. a) run 6: MMA, b) run 21: BA and c) run 23: St. All experiments were carried out at $70{ }^{\circ} \mathrm{C}$ with $\mathrm{IO}=20 \mathrm{~g} \mathrm{~L}^{-1}$, MAA $=5 \mu \mathrm{mol} \mathrm{m}{ }^{-2}$, monomer: $20 \mathrm{wt} \% /$ water and ADIBA: $1 \mathrm{wt}$ $\% /$ monomer.

The MAA concentration was then increased to $10 \mu \mathrm{mol} \mathrm{m} \mathrm{m}^{-2}$ for BA emulsion polymerization (run 22) but the latex got unstable after 10 min polymerization. For styrene, increasing MAA concentration to $10 \mu \mathrm{mol} \mathrm{m} \mathrm{m}^{-2}$ (run 24) and even $20 \mu \mathrm{mol} \mathrm{m} \mathrm{m}^{-2}$ (run 25) led in both cases to stable latexes. TEM showed an armored morphology with IO nanoparticles adhering to the surface of the PSt latex particles, with in addition a lower amount of free IO in the continuous phase for the highest MAA concentration (Figure 12). 
a

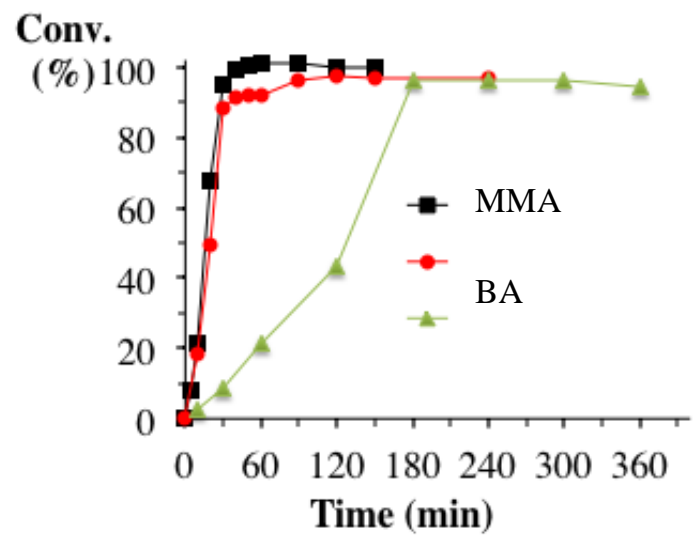

b

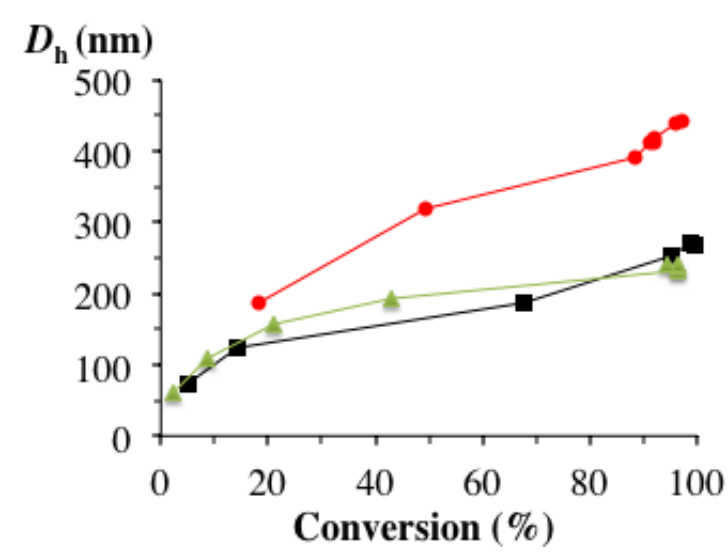

c

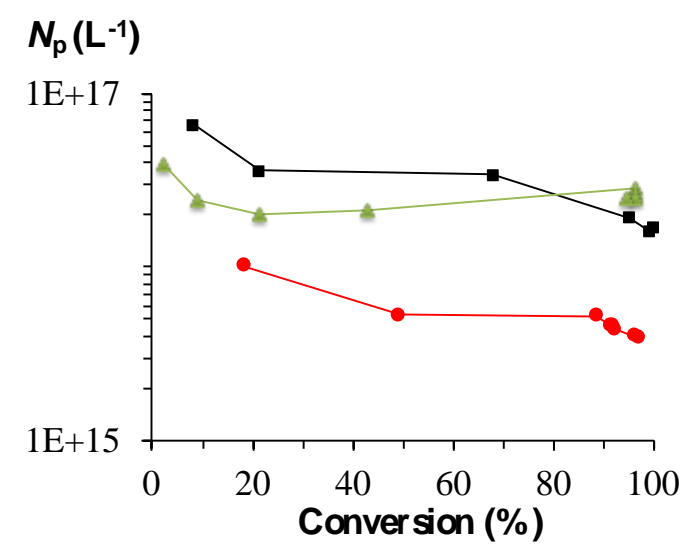

Figure 11. Effect of the nature of the monomer (MMA, BA or St) on the evolution of: a) conversion versus time, b) particle diameter versus conversion, and c) particle number versus conversion for a series of surfactant-free emulsion polymerization experiments performed in the presence of $20 \mathrm{~g} \mathrm{~L}^{-1} \mathrm{IO}$ and $5 \mu \mathrm{mol} \mathrm{m}{ }^{-2} \mathrm{MAA}$ at $\mathrm{pH}$ 2.2. MMA (run 6), BA (run 21) and St (run 23). All experiments were carried out at $70{ }^{\circ} \mathrm{C}$ with monomer: 20 wt \%/water, ADIBA: 1 wt \%/monomer. 

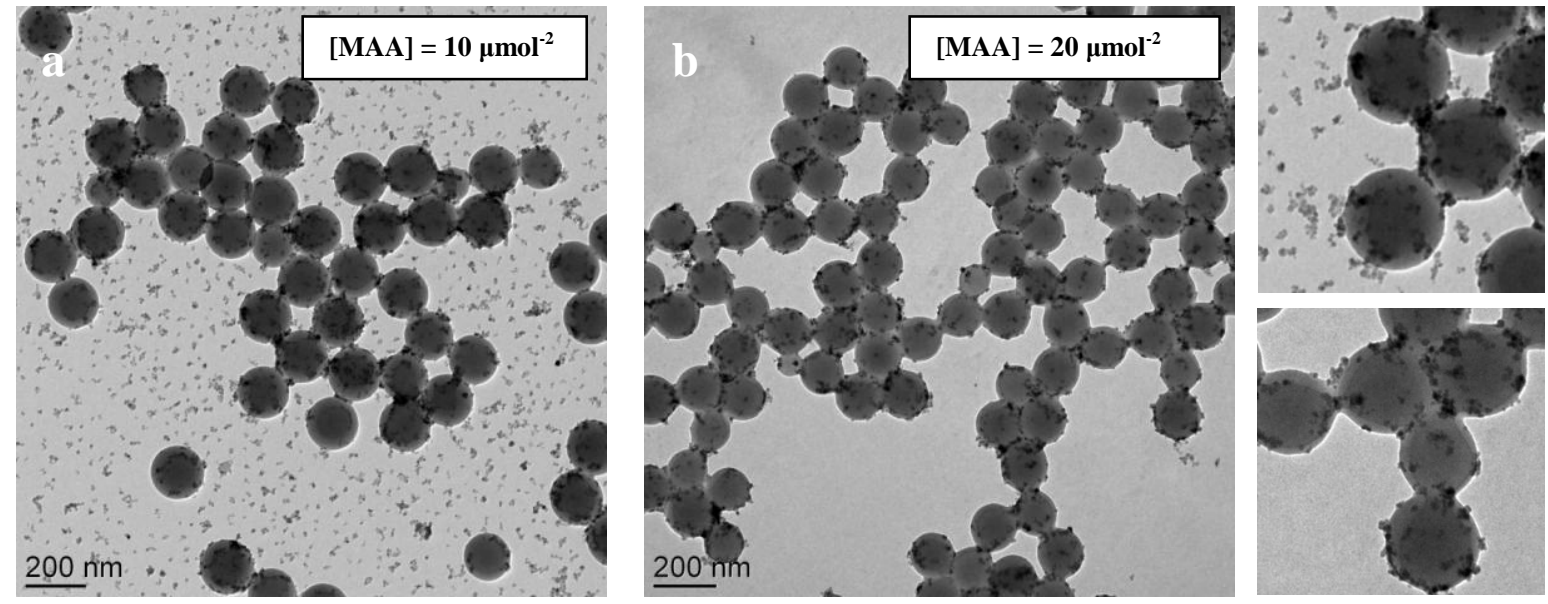

Figure 12. TEM images of PSt latex particles synthesized in the presence of increasing MAA concentrations. a) Run 24: $10 \mu \mathrm{mol} \mathrm{m}{ }^{-2}$ MAA and b) run 25: $20 \mu \mathrm{mol} \mathrm{m}{ }^{-2}$ MAA. Both experiments were carried out at $70{ }^{\circ} \mathrm{C}$ with $\mathrm{IO}=20 \mathrm{~g} \mathrm{~L}^{-1}$, St: $20 \mathrm{wt} \% /$ water and ADIBA: 1 wt $\% /$ St. The images on the right side of the Figure show an enlarged view of the same samples (top: $10 \mu \mathrm{mol} \mathrm{m}{ }^{-2}$ and bottom: $20 \mu \mathrm{mol} \mathrm{m} \mathrm{m}^{-2}$ ).

In good agreement with this observation, the incorporation efficiency steadily increased with increasing MAA concentration (Table 4), reaching $77.5 \mathrm{wt} \%$ for $20 \mu \mathrm{mol} \mathrm{m}{ }^{-2}$ of MAA while the surface coverage increased less due to the concomitant decrease of particle size from 235 to $171 \mathrm{~nm}$. Similarly to MMA polymerization, the higher the MAA concentration, the smaller was the particle size and the higher was consequently the polymerization rate (Figure S7, Supporting Information). In an attempt to increase further the $I E$ value, the MAA amount was raised to $30 \mu \mathrm{mol} \mathrm{m} \mathrm{m}^{-2}$ (run 26) but destabilization occurred after $40 \mathrm{~min}$ of polymerization indicating, as already mentioned above, that IO nanoparticles were not able to stabilize a too large surface area. A too large increase of MAA concentration may also induce IO aggregation resulting in an unstable latex.

The above results can be interpreted in view of the overall composition of the oligomeric radicals formed during the earliest stages of the polymerization and the monomer sequence distribution along the chains. Indeed, as mentioned above, the auxiliary comonomer is an 
important factor that will not only participate in the Pickering emulsion polymerization, but also affect the consumption of the main hydrophobic monomer. This last effect is reflected in the reactivity ratio values. Although there are a lot of reactivity ratios reported in the literature under different reaction conditions, examples of reactivity ratios determined in the aqueous phase of emulsion polymerization are scarce. According to the literature, reactivity ratios for MAA/MMA ${ }^{37,38}$ and MAA/BA ${ }^{45}$ copolymerizations in water indicate that both MMA and BA tend to polymerize faster than MAA resulting in the formation of MMA- or BA-rich oligomers during the nucleation step, which does not favor a strong interaction of IO nanoparticles with the resulting copolymer chains. Most primary particles are thus created by the collapse of MAA-poor growing polymer chains, which does not favor the stabilization of these particles leading to some coalescence. Besides, BA being more hydrophobic than MMA, particle nucleation likely occurs for shorter chains, before enough IO nanoparticles can adhere to the latex particle surface. This assumption is supported by the large particle size, close to $440 \mathrm{~nm}$ for $5 \mu \mathrm{mol} \mathrm{m} \mathrm{m}^{-2}$ of MAA, and a $I E$ value lower than $6 \mathrm{wt} \%$ (run 21 in Table 4).

Similarly to the MAA/MMA and MAA/BA systems, a lot of reactivity ratio values have been reported in the literature for the MAA/St couple, but in most cases $r 1$ and $r_{2}$ determined either in bulk or in solution, are both much lower than one. ${ }^{46,47}$ Although these values may not be fully appropriate under our experimental conditions, they were used as a first estimate. This means that both MAA and St do not want to react with propagating radicals of the same type, resulting in an almost alternating $(r 1 r 2 \approx 0)$ distribution. The primary particles are thus created by the collapse of P(MAA-co-St) alternating copolymer chains, which favors a more efficient capture of IO nanoparticles leading to a more efficient stabilization even if particle nucleation is slower. TEM analysis undoubtedly shows the formation of composite particles with the 
desired armored morphology and small particle size (171 nm for run $25,20 \mu \mathrm{mol} \mathrm{m}{ }^{-2}$ MAA). The $I E$ is also higher than for MMA or BA (close to $78 \mathrm{wt} \%$ for run 25 ).

\subsubsection{AA as auxiliary comonomer}

In addition to the monomer reactivity ratios, another parameter of paramount importance is the solubility of the auxiliary comonomer in water. MAA is effectively water soluble $\left(89 \mathrm{~g} \mathrm{~L}^{-}\right.$ ${ }^{1}$ at $20^{\circ} \mathrm{C}$ in acidic media) but using a more hydrophilic monomer such as AA (miscible with water) will increase its partitioning in favor of the aqueous phase ${ }^{48}$ which should favor a more efficient incorporation of the carboxylic acid units in the initial polymer chains. Following this assumption, two groups of experiments were designed using in both cases AA as auxiliary comonomer in the Pickering emulsion polymerization of either MMA or St (Table $5)$.

For MMA emulsion polymerization, when the AA concentration was increased from 5 to 20 $\mu \mathrm{mol} \mathrm{m}^{-2}$, the polymerization rate increased only slightly (Figure S8, Supporting Information). Increasing AA concentration was expected to increase $N_{\mathrm{p}}$ given that more free radicals and hence more particles are generated, which should have resulted in a higher reaction rate as reported by Polpanich and coworkers ${ }^{49}$ for surfactant-free emulsion copolymerization of St and AA. The particle size of run 28 performed in the presence of a higher amount of AA $(353 \mathrm{~nm})$ was however bigger than that of run $27(253 \mathrm{~nm})$ which could explain why the AA content did not influence the reaction rate. More interestingly, the particle size increased suddenly at the end of the polymerization in both cases. These results can be interpreted in light of the solubility and reactivity of the acid monomer. Reactivity ratios for AA/MMA in bulk ${ }^{50}$ again differ considerably with those determined in solution, ${ }^{51}$ for which the global trend is that $r_{1}<1$ and $r_{2}>1 .^{51,52}$ The growing polymer radical for both monomers thus tends to react with MMA, forming a copolymer consisting mostly of MMA 
leading to poor adhesion to IO nanoparticles in a similar way as discussed above for MAA. However, AA-containing oligomers are more water-soluble than their MAA homologues, and can therefore stay in water for a longer time, which could promote bridging flocculation. Therefore, the particle size increased immediately as more and more AA units were incorporated in the polymer chains after the hydrophobic monomer was consumed. Figure S9 shows TEM images of the obtained PMMA particles (runs 27 and 28). More IO nanoparticles were found to be located at the PMMA surface in run $\left.28(20 \mu \mathrm{mol} \mathrm{m})^{-2}\right)$ than in run $27(5$ $\mu \mathrm{mol} \mathrm{m} \mathrm{m}^{-2}$ ), forming in both cases small nanoclusters while the amount of free IO concurrently decreased. The $I E$ value thus increased from $29.7 \%$ to $73.4 \%$ with increasing AA concentration from $5 \mu \mathrm{mol} \mathrm{m} \mathrm{m}^{-2}$ to $20 \mu \mathrm{mol} \mathrm{m} \mathrm{m}^{-2}$. However, a further increase in the AA concentration (run 29, $30 \mu \mathrm{mol} \mathrm{m}{ }^{-2}$ ) resulted in latex destabilization due to enhanced bridging opportunity.

Table 5. Summary of experimental conditions and results of surfactant-free emulsion polymerizations of MMA or St in the presence of $20 \mathrm{~g} \mathrm{~L}^{-1}$ of IO using AA as auxiliary comonomer. $^{a}$

\begin{tabular}{|c|c|c|c|c|c|c|c|c|c|c|}
\hline Run & $\underset{\left(\mathrm{g} \mathrm{L}^{-1}\right)}{\mathbf{A A}}$ & $\underset{\left(\mu \mathbf{m o l ~ ~ m ^ { - 2 }}\right)}{\mathbf{A A}}$ & $\begin{array}{c}\text { Mono } \\
\text { mer }\end{array}$ & $\mathrm{pH}_{\mathrm{i}}{ }^{b}$ & $\begin{array}{c}\text { Conv. } \\
(\%)\end{array}$ & $\underset{(\mathbf{n m})^{c}}{D_{\mathbf{h}}}$ & Poly $^{c}$ & $N_{\mathbf{p}}\left(\mathbf{L}^{-1}\right)^{d}$ & $\underset{(\%)^{e}}{\text { IE }}$ & $\underset{(\%)^{f}}{\operatorname{Cov}}$ \\
\hline 27 & 1.2 & 5 & MMA & 2.2 & 98 & 253 & 0.19 & $2.010^{16}$ & 29.7 & 7.7 \\
\hline 28 & 4.6 & 20 & MMA & 2.2 & 95 & 353 & 0.22 & $7.110^{15}$ & 73.4 & 14.8 \\
\hline $29^{g}$ & 6.9 & 30 & MMA & 2.2 & $77^{i}$ & $181^{i}$ & 0.12 & I & I & I \\
\hline 30 & 1.2 & 5 & $\mathrm{St}$ & 2.2 & 92 & 223 & 0.04 & $3.110^{16}$ & 31.9 & 6.9 \\
\hline 31 & 4.6 & 20 & $\mathrm{St}$ & 2.2 & 94 & 159 & 0.07 & $8.710^{16}$ & 89.4 & 13.2 \\
\hline $32^{h}$ & 6.9 & 30 & St & 2.2 & $62^{\mathrm{i}}$ & $127^{\mathrm{i}}$ & 0.11 & I & I & I \\
\hline
\end{tabular}

${ }^{a}$ All experiments were carried out for $2 \mathrm{~h}$ with $[\mathrm{IO}]=20 \mathrm{~g} \mathrm{~L}^{-1}$, MMA or St $=20 \mathrm{wt} \% / \mathrm{water}$, ADIBA = $1 \mathrm{wt} \% /$ monomer and $\mathrm{T}=70{ }^{\circ} \mathrm{C} .{ }^{b} \mathrm{pH}$ value of the IO suspension. ${ }^{c}$ Determined by DLS. ${ }^{d}$ Calculated using equation (7). ${ }^{e}$ Calculated using equation (4). ${ }^{f}$ Calculated using equation (5). ${ }^{g}$ Latex destabilization after 10 minutes. ${ }^{h}$ Latex destabilization after 40 minutes. ${ }^{i}$ Monomer conversion and particle size determined just before latex destabilization. 
The TEM images of the PSt latexes stabilized by $20 \mathrm{~g} \mathrm{~L}^{-1} \mathrm{IO}$ (runs 30 and 31) are shown in Figure 13. For $5 \mu \mathrm{mol} \mathrm{m}{ }^{-2}$ AA (run 30), the particle size was around $220 \mathrm{~nm}$, and only a few IO were attached on the PSt surface. When the AA concentration was increased to $20 \mu \mathrm{mol}$ $\mathrm{m}^{-2}$, the particle size significantly decreased $(153 \mathrm{~nm}$, run 31$)$ while the $I E$ value increased from $31.9 \%$ to $89.4 \%$. Similarly to the MAA/St system discussed above, reactivity ratios for AA/Sty ${ }^{53,54,55}$ are such that an alternating copolymer is formed, which likely favors its interaction with the IO surface and the subsequent formation of composite particles. The polymerization became faster when the AA concentration increased (Figure S10) due to the increase of the overall monomer concentration in water. However, when the AA concentration was increased to $30 \mu \mathrm{mol} \mathrm{m} \mathrm{m}^{-2}$, the latex became unstable. The incorporation of too many AA units in the chains led to multiplicity of carboxyl groups in the whole polymer chain, leading to particles destabilization.
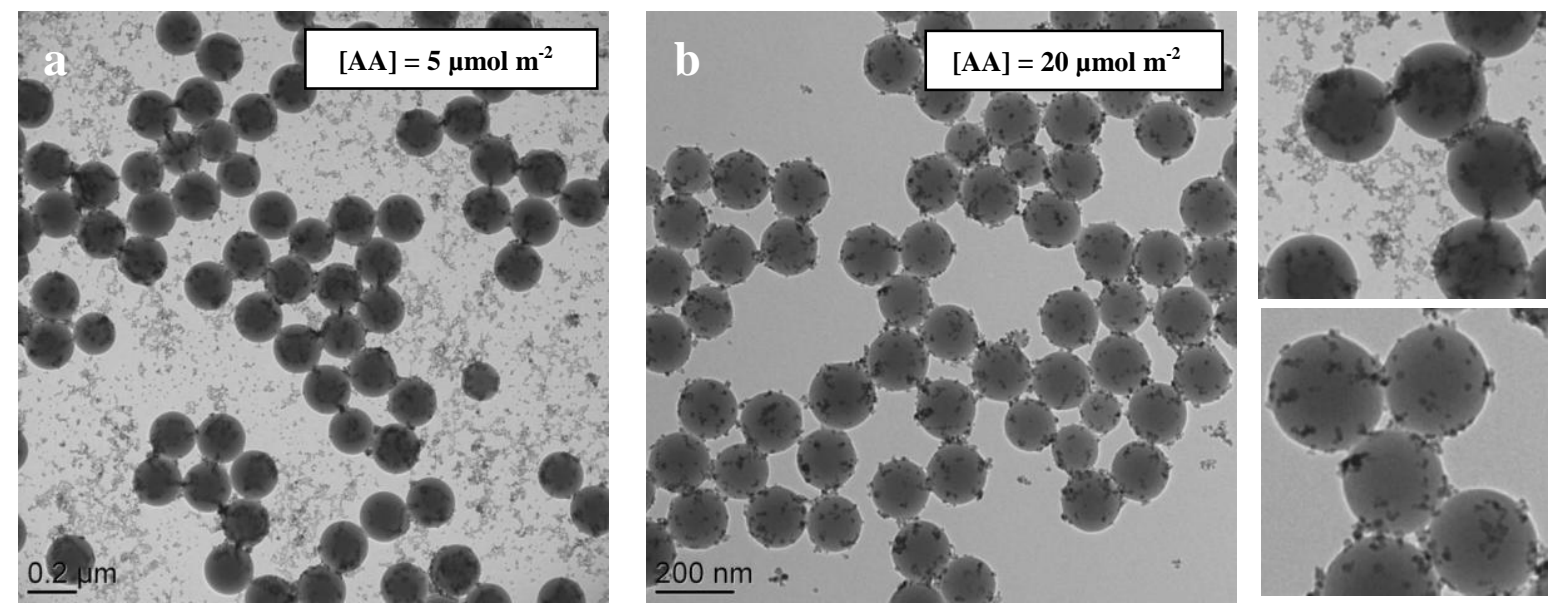

Figure 13. TEM images of PSt latex particles synthesized in the presence of increasing AA concentrations. a) Run 30, AA: $5 \mu \mathrm{mol} \mathrm{m}{ }^{-2}$ and b) run 31, AA: $20 \mu \mathrm{mol} \mathrm{m}{ }^{-2}$. All experiments were carried out at $70{ }^{\circ} \mathrm{C}$ with IO $=20 \mathrm{~g} \mathrm{~L}^{-1}$, St: $20 \mathrm{wt} \% /$ water and ADIBA: $1 \mathrm{wt} \% / \mathrm{St}$. The images on the right side of the Figure show an enlarged view of the same samples (top: 5 $\mu \mathrm{mol} \mathrm{m} \mathrm{m}^{-2}$ and bottom: $20 \mu \mathrm{mol} \mathrm{m}{ }^{-2}$ ). 


\subsection{Mechanism of particle formation}

Based on our experimental observations, we propose the following mechanism for the formation of IO/polymer composite particles. The polymerization starts like in conventional surfactant-free polymerization by the formation of oligoradicals through propagation of the monomer molecules dissolved in water. It is assumed that nucleation occurs when the chain length of the water-soluble oligomeric radicals has reached a critical value, $\mathrm{j}_{\text {crit }}$, above which they precipitate into precursor latex particles. As these precursor particles are solely stabilized by the charges of the initiator fragments, they may undergo limited flocculation to form stable primary particles by homogeneous-coagulative nucleation. Latex stability can be significantly improved by the incorporation of ionogenic functional monomers (such as carboxylic acids). However, in practice, the location of such functional monomers: on the surface of the particles, buried inside the particles or solubilized in water, is difficult to control, and strongly depends on the type and concentration of the reactive monomer and its solubility and

reactivity in the different phases (monomer, water and polymer particles). ${ }^{56}$ In the presence of IO particles, part of the AA- or MAA- containing oligomeric radicals can be trapped at the inorganic particle surface due to favorable interaction with iron oxide, which can significantly modify the affinity of the growing polymer for the inorganic surface, and influence consequently the nucleation process as demonstrated in the present work. As they are growing, the adsorbed oligomers become insoluble and can collide with another IO particle (with or without adsorbed oligomers) or with unstable precursor particles resulting into mature particles. According to this scenario, the size and stability of the final latex particles strongly depends on the capacity of the oligomeric radicals to effectively adsorb on the IO surface and subsequently heterocoagulate with unstable growing latex particles, which in turns depends on the suspension $\mathrm{pH}$, and on the concentration, water solubility and reactivity 
of the functional monomer. Moreover, upon heterocoagulation, the IO particles with adsorbed functional oligomers are maintained at the particle surface, which allows for a more efficient use of the carboxylic acid monomer compared with surfactant-free polymerizations performed under identical conditions in the absence of IO, where the reactive monomer may be buried inside the particles depending on the suspension $\mathrm{pH}$ and its water solubility. This likely explains why such small particles are nucleated in the presence of IO despite their low surface coverage. For successful Pickering emulsion polymerization and a high IO incorporation efficiency, the collision process must be fast with respect to the timescales of particle nucleation and growth. ${ }^{57}$ This thus requires that the oligomers contain a minimum amount of carboxylic acid units to adsorb on the IO surface before they form new polymer particles. Indeed, if the oligomeric radicals contain a too high amount of hydrophobic monomer, they will display only minor interaction with the IO surface resulting in separate populations of particles, and hence in a low surface coverage and a low IO incorporation efficiency. On the other hand, a too high concentration of the carboxylic acid monomer will result in fully watersoluble oligomers, which in addition to representing a waste of functional monomer, may favor bridging flocculation and/or IO aggregation. Therefore, an alternating incorporation of both monomers seems to be the best compromise as it favors oligomer adsorption on the IO surface and subsequent formation of composite particles, without affecting IO or latex colloidal stability.

\subsection{Magnetic properties}

Magnetization curves of pure IO and some selected samples measured at room temperature are shown in Figure 14. In superparamagnetic materials, the values of remanent magnetization $\left(M_{\mathrm{r}}\right)$, and coercivity $\left(H_{\mathrm{c}}\right)$ are zero, and the two magnetization curves go through the zero point 
and overlap. Figure 14 indicates that the composite latex particles are superparamagnetic at room temperature. The specific saturation magnetization $\left(M_{\mathrm{s}}\right)$ of pure IO is $60 \mathrm{emu} \mathrm{g}^{-1}$. As expected, this value is in agreement with the saturation magnetization of maghemite and is smaller than that of the bulk material or of magnetite. ${ }^{58}$ The saturation magnetizations of the PMMA and PSt composite particles are 4.3 and $5.3 \mathrm{emu} \mathrm{g}^{-1}$, respectively, which agrees well with the IO content determined by TGA, indicating that the polymerization process did not affect the magnetic properties of the IO particles.

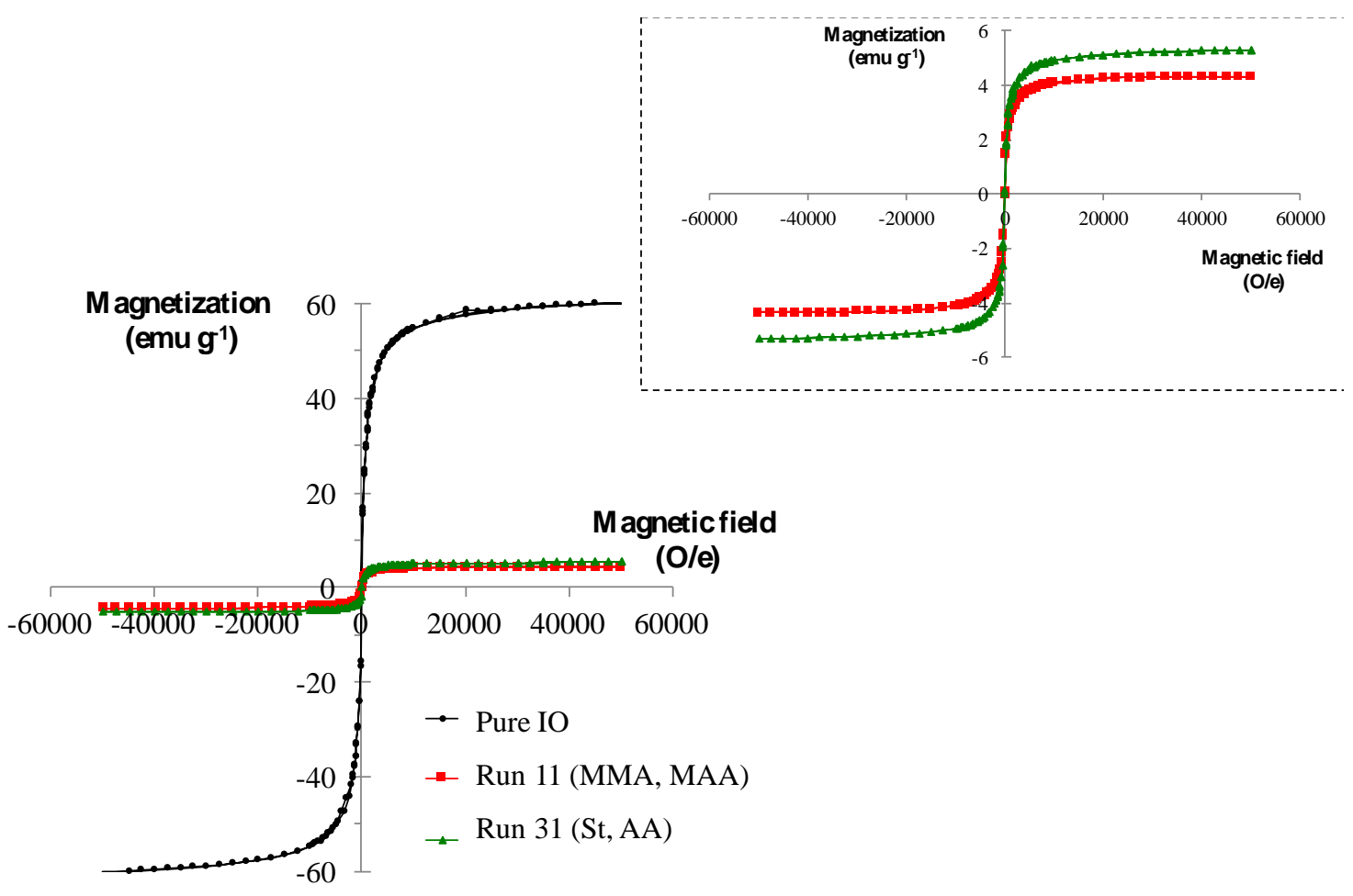

Figure 14. Plots of magnetization as a function of the magnetic field for as-synthesized IO nanoparticles and for polymer/IO composite latex particles synthesized by surfactant-free emulsion polymerization in the presence of $20 \mathrm{~g} \mathrm{~L}^{-1} \mathrm{IO}$ using MAA or AA as auxiliary comonomers. Run 11 (MMA, $30 \mu \mathrm{mol} \mathrm{m}{ }^{-2} \mathrm{MAA}$ ) and run 31 (St, $\left.20 \mu \mathrm{mol} \mathrm{m}{ }^{-2} \mathrm{AA}\right)$. The inset shows a magnification of the magnetization curves of runs 11 and 31. 


\section{CONCLUSIONS}

Polymer/IO composite latex particles with a patchy IO overlayer have been synthesized through Pickering emulsion polymerization of MMA and other hydrophobic monomers (namely BA and St) using ultrasmall superparamagnetic IO nanoparticles as solid stabilizer, in the absence of surfactant. An auxiliary comonomer (MAA or AA) was initially used to promote IO adhesion to the surface of the generated polymer particles. The auxiliary comonomers however poorly adsorbed onto IO, and the formation of the composite latexes was actually promoted by the formation of AA or MAA containing oligomers which can adsorb more strongly due to the presence of multiple bonding sites. Accordingly, the particle size decreased with increasing the amount of comonomer or IO content due to a more efficient oligomer adsorption on the IO surface resulting in more favorable interactions between the IO-functionalized particles and the growing latex particles, while the reaction rate increased due to the increased number of reaction loci. The suspension $\mathrm{pH}$ was also shown to be a determinant parameter as a higher $I E$ value was obtained at $\mathrm{pH} 4.5$ than at $\mathrm{pH}$ 2.2 in agreement with the adsorption isotherms. The Pickering emulsion polymerization process was also strongly influenced by the reactions taking place in water and the composition of the oligomeric radicals. The later should incorporate a minimum amount of carboxylic acid groups to adsorb on the IO surface and favor the heterocoagulation process. However, a too high concentration of auxiliary comonomer can also favor IO aggregation resulting in an irregular distribution of the superparamagnetic colloids at the latex particle surface or to bridging flocculation. The most successful results were obtained for St polymerization using AA as auxiliary comonomer. The reactivity ratios of these two monomers and the higher water solubility of AA as compared to MAA tend to promote the formation of AA-rich copolymers displaying favorable interactions with the IO surface 
without affecting the IO or composite latex particles stability. According to this scenario, the resulting IO particles with adsorbed oligomers on their surface would exhibit appropriate surface-activity to contribute to the stabilization of the polymer particle nuclei generated in the aqueous phase, resulting in the formation of small latex particles with high polymerization rates.

\section{ASSOCIATED CONTENT}

\section{Supporting Information}

The Supporting Information is available free of charge on the ACS Publications website at DOI:

FTIR spectra of pristine IO, MAA and IO/MAA adsorption complexes ; IO DLS particle size and $\zeta$ potential as a function of the MAA concentration for two $\mathrm{pH}$ values; TEM images of runs $1-4,13,6,14,17-19$ and 27-28 and kinetics studies for runs 2, 7, 8, 23-25, 27-28 and 3031.

\section{ACKNOWLEDGMENTS}

Financial support from the Chinese Scholarship Council is gratefully acknowledged.

\section{REFERENCES}

(1) Bourgeat-Lami, E.; Lansalot, M. Organic/Inorganic Composite Latexes: The Marriage of Emulsion Polymerization and Inorganic Chemistry. Adv. Polym. Sci. 2010, 233, 53-123.

(2) Jeong, U.; Teng, X.; Wang, Y.; Yang, H.; Xia, Y. Superparamagnetic Colloids: Controlled Synthesis and Niche Applications. Adv. Mater. 2007, 19, 33-60. 
(3) (a) Arruebo, M.; Fernández-Pacheco, R.; Ibarra, M. R.; Santamaría, J. Magnetic nanoparticles for drug delivery. Nano Today 2007, 2, 22-32; (b) Josephson, L.; Perez, J. M.; Weissleder, R. Magnetic Nanosensors for the Detection of Oligonucleotide Sequences. Angew. Chem. Int. Ed. 2001, 113, 3304-3306; (c) Jun, Y.-w.; Seo, J.-w.; Cheon, J. Nanoscaling Laws of Magnetic Nanoparticles and Their Applicabilities in Biomedical Sciences. Acc. Chem. Res. 2008, 41, 179-189; (d) Na, H. B.; Song, I. C.; Hyeon, T. Inorganic Nanoparticles for MRI Contrast Agents. Adv. Mater. 2009, 21, 2133-2148; (e) Pankhurst, Q. A.; Thanh, N. T. K.; Jones, S. K.; Dobson, J. Progress in applications of magnetic nanoparticles in biomedicine. J. Phys. D: Appl. Phys. 2009, 42, 224001-224015; (f) Pankhurst, Q. A.; Connolly, J.; Jones, S. K.; Dobson, J. Applications of magnetic nanoparticles in biomedicine. J. Phys. D: Appl. Phys. 2003, 36, 167-181; (g) Sun, C.; Lee, J. S. H.; Zhang, M. Magnetic nanoparticles in MR imaging and drug delivery. Adv. Drug Deliv. Rev. 2008, 60, 1252-1265; (h) Perez, J. M.; Josephson, L.; O'Loughlin, T.; Hogemann, D.; Weissleder, R. Magnetic relaxation switches capable of sensing molecular interactions. Nat. Biotechnol. 2002, 20, 816-820; (i) Flesch, C.; Unterfinger, Y.; Bourgeat-Lami, E.; Duguet, E.; Delaite, C.; Dumas, P. Poly(ethylene glycol) surface coated magnetic particles. Macromolecular Rapid Communications 2005, 26, 1494-1498; (j) Flesch, C.; Bourgeat-Lami, E.; Mornet, S.; Duguet, E.; Delaite, C.; Dumas, P. Synthesis of colloidal superparamagnetic nanocomposites by grafting poly(epsilon-caprolactone) from the surface of organosilanemodified maghemite nanoparticles. Journal of Polymer Science Part a-Polymer Chemistry 2005, 43, 3221-3231.

(4) Rahman, M. M.; Elaissari, A., Organic-Inorganic Hybrid Magnetic Latex. In Hybrid Latex Particles: Preparation with (Mini)emulsion Polymerization, Van Herk, M. A.; Landfester, K., Eds. Springer Berlin Heidelberg: Berlin, Heidelberg, 2010; pp 237-281.

(5) Schrade, A.; Landfester, K.; Ziener, U. Pickering-type stabilized nanoparticles by heterophase polymerization. Chem. Soc. Rev. 2013, 42, 6823-39.

(6) Ramsden, W. Separation of Solids in the Surface-Layers of Solutions and 'Suspensions' (Observations on Surface-Membranes, Bubbles, Emulsions, and Mechanical Coagulation). Preliminary Account. Proc. R. Soc. London, Ser. 1903, 72, 156-164.

(7) Pickering, S. U. Emulsions. J. Chem. Soc., Trans. 1907, 91, 2001-2021.

(8) (a) Brunier, B.; Sheibat-Othman, N.; Chevalier, Y.; Bourgeat-Lami, E. Partitioning of Laponite Clay Platelets in Pickering Emulsion Polymerization. Langmuir 2016, 32, 112-124; (b) Brunier, B.; Sheibat-Othman, N.; Chniguir, M.; Chevalier, Y.; Bourgeat-Lami, E. 
Investigation of Four Different Laponite Clays as Stabilizers in Pickering Emulsion Polymerization. Langmuir 2016, 32, 6046-6057.

(9) Faridi-Majidi, R.; Sharifi-Sanjani, N.; Agend, F. Encapsulation of magnetic nanoparticles with polystyrene via emulsifier-free miniemulsion polymerization. Thin Solid Films 2006, 515, 368-374.

(10) Yin, D.; Du, X.; Liu, H.; Zhang, Q.; Ma, L. Facile one-step fabrication of polymer microspheres with high magnetism and armored inorganic particles by Pickering emulsion polymerization. Colloids Surf. A. Physicochem. Eng. Asp. 2012, 414, 289-295.

(11) Ahn, W. J.; Jung, H. S.; Choi, H. J. Pickering emulsion polymerized smart magnetic poly(methyl methacrylate)/Fe2O3composite particles and their stimulus-response. $R S C A d v$. 2015, 5, 23094-23100.

(12) Xu, Z.; Xia, A.; Wang, C.; Yang, W.; Fu, S. Synthesis of raspberry-like magnetic polystyrene microspheres. Mater. Chem. Phys. 2007, 103, 494-499.

(13) Kim, Y. J.; Liu, Y. D.; Seo, Y.; Choi, H. J. Pickering-Emulsion-Polymerized Polystyrene/ $\mathrm{Fe}_{2} \mathrm{O}_{3}$ Composite Particles and Their Magnetoresponsive Characteristics. Langmuir 2013, 29, 4959-4965.

(14) Chen, M.; Wu, L.; Zhou, S.; You, B. Synthesis of Raspberry-like PMMA/SiO 2 Nanocomposite Particles via a Surfactant-Free Method. Macromolecules 2004, 37, 9613 9619.

(15) Sheibat-Othman, N.; Bourgeat-Lami, E. Use of Silica Particles for the Formation of Organic-Inorganic Particles by Surfactant-Free Emulsion Polymerization. Langmuir 2009, 25, 10121-10133.

(16) Bourgeat-Lami, E.; Guimaraes, T. R.; Pereira, A. M. C.; Alves, G. M.; Moreira, J. C.; Putaux, J.-L.; dos Santos, A. M. High Solids Content, Soap-Free, Film-Forming Latexes Stabilized by Laponite Clay Platelets. Macromol. Rapid Commun. 2010, 31, 1874-1880.

(17) Amalvy, J. I.; Percy, M. J.; Armes, S. P. Synthesis and Characterization of Novel FilmForming Vinyl Polymer/Silica Colloidal Nanocomposites. Langmuir 2011, 17, 4770-4778.

(18) Zgheib, N.; Putaux, J.-L.; Thill, A.; D'Agosto, F.; Lansalot, M.; Bourgeat-Lami, E. Stabilization of Miniemulsion Droplets by Cerium Oxide Nanoparticles: A Step toward the Elaboration of Armored Composite Latexes. Langmuir 2012, 28, 6163-6174.

(19) Massart, R. Preparation of Aqueous Magnetic Liquids in Alkaline and Acidic Media. Mag. IEEE Trans. 1981, 17, 1247-1248.

(20) Massart, R.; Dubois, E.; Cabuil, V.; Hasmonay, E. Preparation and properties of monodisperse magnetic fluids. J. Magn. Magn. Mater. 1995, 149, 1-5. 
(21) Handbook of Chemistry and Physics. CRC Press: Cleveland, OH, 1977.

(22) Joumaa, N.; Toussay, P.; Lansalot, M.; Elaissari, A. Surface modification of iron oxide nanoparticles by a phosphate-based macromonomer and further encapsulation into submicrometer polystyrene particles by miniemulsion polymerization. J. Polym. Sci., Part A: Polym. Chem. 2007, 46, 327-340.

(23) Yu, S.; Chow, G. M. Carboxyl group $(\mathrm{CO} 2 \mathrm{H})$ functionalized ferrimagnetic iron oxide nanoparticles for potential bio-applications. J. Mater. Chem. 2004, 14, 2781-2786.

(24) Teixeira, R. F. A.; McKenzie, H. S.; Boyd, A. A.; Bon, S. A. F. Pickering Emulsion Polymerization Using Laponite Clay as Stabilizer To Prepare Armored "Soft" Polymer Latexes. Macromolecules 2011, 44, 7415-7422.

(25) Drmota, A.; Kosak, A.; Znidarsic, A. A Mechanism for the adsorption of carboxylic acids onto the surface of magnetic nanoparticles Materials and Technology 2008, 42, 79-83.

(26) Harris, L. A.; Goff, J. D.; Carmichael, A. Y.; Riffle, J. S.; Harburn, J. J.; St Pierre, T. G.; Saunders, M. Magnetite Nanoparticle Dispersions Stabilized with Triblock Copolymers. Chem. Mater. 2003, 15, 1367-1377.

(27) Smoluchowski, M. v. Attempt for a mathematical theory of kinetic coagulation of colloid solutions. Z Phys. Chem. 1917, 92, 129-168.

(28) Chern, C. S. Emulsion polymerization mechanisms and kinetics. Prog. Polym. Sci. 2006, 31, 443-486.

(29) Fitch, R. M. The Homogeneous Nucleation of Polymer Colloids. Brit. Polym. J. 1973, 5, 467-483.

(30) Hwang, Y. S.; Lenhart, J. J. Adsorption of C4-Dicarboxylic Acids at the Hematite/Water Interface. Langmuir 2008, 24, 13934-13943.

(31) Katchalsky, A.; Blauer, G. Kinetics of methacrylic acid polymerization in aqueous solution. T. Faraday Soc. 1951, 47, 1360-1370.

(32) Ibarra-Montaño, E. L.; Rodríguez-Laguna, N.; Sánchez-Hernández, A.; RojasHernández, A. Determination of pKa Values for Acrylic, Methacrylic and Itaconic Acids by 1H and 13C NMR in Deuterated Water. J. Appl. Sol. Chem. Model. 2015, 4, 7-18.

(33) Sperling, R. A.; Parak, W. J. Surface modification, functionalization and bioconjugation of colloidal inorganic nanoparticles. Philos. Trans. A Math. Phys. Eng. Sci. 2010, 368, 13331383.

(34) Rebuttini, V. Functional iron oxide-based hybrid nanostructures. MathematischNaturwissenschaftliche Fakultät, 2014. 
(35) Goodman, A. L.; Bernard, E. T.; Grassian, V. H. Spectroscopic Study of Nitric Acid and Water Adsorption on Oxide Particles: Enhanced Nitric Acid Uptake Kinetics in the Presence of Adsorbed Water. J. Phys. Chem. A 2001, 105, 6443-6457.

(36) Georgiev, G. S.; Dakova, I. G. Solvent effect on the methacrylic acid-methyl methacrylate radical copolymerization. Analytical estimation by linear and nonlinear solvation energy relationships. Macromol. Chem. Phys. 1994, 195, 1695-1707.

(37) Bezuglyi, V. D.; Voskresenskaya, I. B.; Alekseev, T. A.; Gerner, M. M. Vysokomol. Soedin., Ser. A 1972, 14, 540.

(38) Daswani, P.; Rheinhold, F.; Ottink, M.; Staal, B.; van Herk, A. Method to isolate and characterize oligomers present in the aqueous phase in emulsion copolymerization. Eur. Polym. J. 2012, 48, 296-308.

(39) Ryabov, A. V.; Semchikov, Y. D.; Slavnitskaya, N. N. Vysokomol. Soedin., Ser. A. 1970, 12,553 .

(40) Percy, M. J.; Amalvy, J. I.; Randall, D. P.; Armes, S. P.; Greaves, S. J.; Watts, J. F. Synthesis of Vinyl Polymer Silica Colloidal Nanocomposites Prepared Using Commercial Alcoholic Silica Sols. Langmuir 2004, 20, 2184-2190.

(41) Yin, G.; Zheng, Z.; Wang, H.; Du, Q. Slightly surface-functionalized polystyrene microspheres prepared via Pickering emulsion polymerization using for electrophoretic displays. J. Colloid Interface Sci. 2011, 361, 456-64.

(42) Liu, Y.; Chen, X.; Wang, R.; Xin, J. H. Polymer microspheres stabilized by titania nanoparticles. Mater. Lett. 2006, 60, 3731-3734.

(43) van Herk, A. M.; Gilbert, R. G., Emulsion Polymerisation. In Chemistry and Technology of Emulsion Polymerisation, John Wiley \& Sons Ltd: 2013; pp 43-73.

(44) Beuermann, S.; Buback, M. Rate coefficients of free-radical polymerization deduced from pulsed laser experiments. Prog. Polym. Sci. 2002, 27, 191-254.

(45) Greenley, R. Z. Recalculation of Some Reactivity Ratios. J. Macromol. Sci. A. 1980, 14, 445-515.

(46) Chapin, E. C.; Ham, G. E.; Mills, C. L. Copolymerization. VII. Relative Rates of Addition of Various Monomers in Copolymerization. J. Polym. Sci. 1949, 4, 597-604.

(47) Sahloul, N.; Penlidis, A. Styrene/Methacrylic Acid Monomer Reactivity Ratio Estimation in Bulk and Solution at High Temperatures. Polym. Plast. Technol. Eng. 2005, 44, 771-782.

(48) (a) Shoaf, G. L.; Poehlein, G. W. Partition of Carboxylic Acids in an Emulsion Copolymerization System. Ind. Eng. Chem. Res. 1990, 29, 1701-1709; (b) Tripathi, A. K.; 
Sundberg, D. C. Partitioning of Functional Monomers in Emulsion Polymerization: Distribution of Carboxylic Acid Monomers between Water and Monomer Phases. Ind. Eng. Chem. Res. 2013, 52, 3306-3314.

(49) Polpanich, D.; Tangboriboonrat, P.; Elaïssari, A. The effect of acrylic acid amount on the colloidal properties of polystyrene latex. Colloid Polym. Sci. 2005, 284, 183-191.

(50) Brar, A. S.; Arunan, E.; Kapur, G. S. Sequence Determination in Acrylic Acid-Methyl Methacrylate Copolymers by 13C and 1H NMR Spectroscopy. Polym. J. 1989, 21, 689-695.

(51) Ekpenyong, K. I. Monomer reactivity ratios: Acrylic acid-methylmethacrylate copolymerization in dimethylsulfoxide. J. Chem. Educ. 1985, 62, 173.

(52) Kerber, V. R.; Glamann, H. Lösungsmitteleinflüsse auf die copolymerisationsparameter des systems methylmethacrylat/acrylsäure. Makromol. Chem. 1967, 100, $290-294$.

(53) Borchardt, J. K. Calculation of Reactivity Ratios and Sequence Distributions in Copolymers from Monomers 13C-NMR Data. J. Macromol. Sci. A. 1985, 22, 1711-1733.

(54) Wang, S.; Poehlein, G. W. Investigation of the Sequence Distribution of Bulk and Emulsion Styrene-Acrylic Acid Copolymers by 'H-and 13C-NMR. J. Appl. Polym. Sci. 1993, 49, 991-1001.

(55) Lessard, B.; Schmidt, S. C.; Marić, M. Styrene/Acrylic Acid Random Copolymers Synthesized by Nitroxide-Mediated Polymerization: Effect of Free Nitroxide on Kinetics and Copolymer Composition. Macromolecules 2008, 41, 3446-3454 and references therein.

(56) Guillaume, J. L.; Pichot, C.; Guillot, J. Emulsifier-Free Emulsion Copolymerization of Styrene and Butyl Acrylate. Kinetic Studies in the Presence of Ionogenic Comonomers. $J$. Polym. Sci. Part A. Polym. Chem. 1988, 26, 1937-1959.

(57) Teixeira, R. F. A.; Bon, S. A. F. Physical Methods for the Preparation of Hybrid Nanocomposite Polymer Latex Particles. Adv. Polym. Sci. 2010, 233, 19-52.

(58) Rebodos, R. L.; Vikesland, P. J. Effects of Oxidation on the Magnetization of Nanoparticulate Magnetite. Langmuir 2010, 26, 16745-16753. 